\title{
Simultaneous administration of cocaine and caffeine dysregulates HCN and T-type channels
}

\author{
María Celeste Rivero-Echeto ${ }^{1}$ - Paula P. Perissinotti ${ }^{1}$ - Carlota González-Inchauspe ${ }^{1}$ • Lucila Kargieman ${ }^{1}$. \\ Verónica Bisagno $^{2} \cdot$ Francisco J. Urbano $^{1,3,4}$ [D
}

Received: 6 October 2020 / Accepted: 18 November 2020 / Published online: 25 November 2020

(C) Springer-Verlag GmbH Germany, part of Springer Nature 2020

\begin{abstract}
Rationale The abuse of psychostimulants has adverse consequences on the physiology of the central nervous system. In Argentina, and other South American countries, coca paste or "PACO" (cocaine and caffeine are its major components) is massively consumed with deleterious clinical consequences for the health and well-being of the general population. A scant number of studies have addressed the consequences of stimulant combination of cocaine and caffeine on the physiology of the somatosensory thalamocortical (ThCo) system.

Objectives Our aim was to study ion conductances that have important implications regulating sleep-wake states 24-h after an acute or chronic binge-like administration of a cocaine and caffeine mixture following previously analyzed pasta base samples ("PACO"-like binge") using mice.

Methods We randomly injected (i.p.) male C57BL/6JFcen mice with a binge-like psychostimulants regimen during either 1 day (acute) or 1 day on/1 day off during 13 days for a total of 7 binges (chronic). Single-cell patch-clamp recordings of VB neurons were performed in thalamocortical slices $24 \mathrm{~h}$ after the last psychostimulant injection. We also recorded EEG/EMG from mice $24 \mathrm{~h}$ after being systemically treated with chronic administration of cocaine + caffeine versus saline, vehicle.

Results Our results showed notorious changes in the intrinsic properties of the VB nucleus neurons that persist after 24-h of either acute or chronic binge administrations of combined cocaine and caffeine ("PACO"-like binge). Functional dysregulation of HCN (hyperpolarization-activated cyclic nucleotide-gated) and T-type VGC (voltage-gated calcium) channels was described 24-h after acute/chronic "PACO"-like administrations. Furthermore, intracellular basal $\left[\mathrm{Ca}^{2+}\right]$ disturbances resulted a key factor that modulated the availability and the activation of T-type channels, altering T-type "window currents." As a result, all these changes ultimately shaped the low-threshold spikes (LTS)-associated $\mathrm{Ca}^{2+}$ transients, regulated the membrane excitability, and altered sleep-wake transitions.

Conclusion Our results suggest that deleterious consequences of stimulants cocaine and caffeine combination on the thalamocortical physiology as a whole might be related to potential neurotoxic effects of soaring intracellular $\left[\mathrm{Ca}^{2+}\right]$.
\end{abstract}

María Celeste Rivero-Echeto and Paula P. Perissinotti contributed equally to this work.

Carlota González-Inchauspe In memoriam (1968-June 2020)

Francisco J. Urbano

fjurbano@fbmc.fcen.uba.ar

María Celeste Rivero-Echeto

macelesteriveroecheto@gmail.com

Paula P. Perissinotti

peripali@ fbmc.fcen.uba.ar

Lucila Kargieman

lukargieman@fbmc.fcen.uba.ar

Verónica Bisagno

vbisagno@ffyb.uba.ar
1 CONICET-Universidad de Buenos Aires, Instituto de Fisiología, Biología Molecular y Neurociencias (IFIBYNE), Ciudad de Buenos Aires, Argentina

2 CONICET-Universidad de Buenos Aires, Instituto de Investigaciones Farmacológicas (ININFA), Ciudad de Buenos Aires, Argentina

3 Universidad de Buenos Aires, Facultad de Ciencias Exactas y Naturales, Departamento de Fisiología, Biología Molecular y Celular "Dr. Héctor Maldonado", Ciudad de Buenos Aires, Argentina

4 IFIBYNE (UBA-CONICET), Intendente Güiraldes 2160, Ciudad Universitaria, C1428EGA Ciudad Autónoma de Buenos Aires, Argentina 
Keywords Cocaine $\cdot$ Caffeine $\cdot$ Thalamic ventrobasal $\cdot$ Calcium imaging $\cdot \mathrm{HCN}$ channes $\cdot$ T-type channels $\cdot$ Mouse

\begin{tabular}{|c|c|}
\hline \multicolumn{2}{|c|}{ Abbreviations } \\
\hline ACSF & Artificial cerebrospinal fluid \\
\hline APs & Action potentials \\
\hline CNQX & $\begin{array}{l}\text { 6-Cyano-7-nitroquinoxaline-2,3-dione } \\
\text { disodium salt hydrate }\end{array}$ \\
\hline $\mathrm{HCN}$ & $\begin{array}{l}\text { Hyperpolarization-activated cyclic } \\
\text { nucleotide-gated }\end{array}$ \\
\hline VGC & Voltage-gated calcium \\
\hline DL-AP5 & DL-2-amino-5-phosphonovaleric acid \\
\hline EGTA & $\begin{array}{l}\text { Ethylene glycol-bis ( } \beta \text {-aminoethyl } \\
\text { ether)-N,N,N',N'-tetraacetic acid } \\
\text { tetrasodium salt }\end{array}$ \\
\hline LTS & Low-threshold voltage-gated \\
\hline & T-type-mediated spike \\
\hline TEA & Tetraethylammonium \\
\hline ThCo & Thalamocortical \\
\hline TTX & Tetrodotoxin \\
\hline VB & Ventrobasal \\
\hline
\end{tabular}

\section{Introduction}

The abuse of psychostimulants represents a health problem and includes adverse consequences on the physiology of the central nervous system. Cannabinoids, opiates, cocaine, amphetamine, methamphetamine, and "ecstasy" stand out among the most commonly abused drugs (Cadet and Bisagno 2013; Cadet et al. 2014), which are combined with newly designed drugs (bath salts) whose deleterious effects are still far from being fully known (López-Rodriguez and Viveros 2019). In South America and especially in Argentina, the Oriental Republic of Uruguay and other South American countries, coca "paste" or "PACO" (which represents another inhalable form of cocaine besides crack) is massively consumed (Prieto et al. 2016; Schwarzkopf et al. 2018).

López-Hill et al. (2011) have described the most common components of the cocaine base "paste" samples seized by the Uruguayan police, showing that the percentage of cocaine varies between 20 and 50\%, while there is an alarmingly high percentage of caffeine that reaches between $20 \%$ and 30\% (López-Hill et al. 2011). Caffeine used as an adulterant, volatile when smoked, would work in synergy with cocaine to increase the stimulating effect and its consumption is associated with a very high abuse liability and toxicity (Prieto et al. 2016, 2020). In mice, systemic chronic administration of a combination of cocaine and caffeine that emulated the proportion described on pasta base samples (López-Hill et al. 2011) induced an initial increase in motor activity (Muñiz et al. 2016) and altered the expression of genes involved in glutamatergic and dopaminergic neurotransmission in the mesolimbic reward system (Muñiz et al. 2017). Caffeine effects on thalamocortical ( $\mathrm{ThCo}$ ) neurons have been described to involve altered calcium release and reuptake by the endoplasmic reticulum (Coulon et al. 2009; Rankovic et al. 2010), while inhibiting phosphodiesterase (Fontanez and Porter 2006; Rankovic et al. 2010) and blocking adenosine receptors that play a central role on wake-sleep cycles (Lazarus et al. 2011). Indeed, caffeine enhanced wakefulness-induced effects of cocaine in rodents when using coca "paste" samples during electroencephalographic recordings (Schwarzkopf et al. 2018).

Cocaine alters somatosensory ThCo processing through the increment of monoamine synaptic levels (Urbano et al. 2015; Bisagno et al. 2016; Urbano and Bisagno 2017). Excessive cocaine use can cause manifestations extensively related to alter ThCo processing (Behrendt 2006) like seizures and delusions accompanied by hallucinations (Hanson et al. 1999; Devlin and Henry 2008).

A scant number of studies have addressed the consequences of stimulants combination of cocaine and caffeine on the physiology of the somatosensory ThCo system. In this study, mice were injected with a mixture of cocaine and caffeine (PACO-like binge), whose composition resembles previously analyzed "cocaine paste base" samples (López-Hill et al. 2011). We focused on the study of how PACO-like administrations alter ion conductances that have importants implications regulating sleep-wake states. In particular, $\mathrm{I}_{\mathrm{H}}$ (the current mediated by hyperpolarization-activated cyclic nucleotide-gated channels, i.e., $\mathrm{HCN}$ channels) and $\mathrm{I}_{\mathrm{T}}$ (T-type calcium current mediated by $\mathrm{Ca}_{\mathrm{V}} 3$ channels) are key conductances known to modulate neuronal activity within the subthreshold voltage range (Jahnsen and Llinás 1984a, b; Urbano and Bisagno 2017; Zobeiri et al. 2018, 2019). Firstly, we characterized $\mathrm{I}_{\mathrm{H}}$ and $\mathrm{I}_{\mathrm{T}}$ activity in mice ThCo ventrobasal (VB) neurons 24-h after an acute administration of a "PACO"-like binge. Then, we assessed whether the acute alterations that we found persisted or changed 24-h after a chronic administration; studying also sleep-wake transitions during electroencephalography sleep recordings. We found a functional dysregulation of HCN and T-type channels 24-h after acute/chronic "PACO"-like adminintrations. In addition, intracellular basal $\left[\mathrm{Ca}^{2+}\right]$ alterations modulated the availability and the activation of T-type channels, affecting T-type "window currents." As a result, all these changes ultimately shaped LTSassociated $\mathrm{Ca}^{2+}$ transients, regulated the membrane excitability, and altered sleep-wake transitions. 


\section{Materials and methods}

\section{Animals}

We used male C57BL/6JFcen mice (25-35 days old, 25$30 \mathrm{~g}$ ). Central Animal Facility at the University of Buenos Aires, animal protocol \#50-2015, and \#67-2015). Principles of animal care were in accordance with the ARRIVE guidelines and CONICET (2003), and approved by its authorities using OLAW/ARENA directives (NIH, Bethesda, MD, USA). Mice were monitored regularly by researchers in charge of handling and injections. No exclusion criteria were pre-determined. None of the mice died from treatment or injection procedure. We minimized suffering by carefully injecting the mice, placing the injected animals in a warm and comfortable environment in their home cage.

Researcher blindly and randomly injected mice. Researchers in charge of electrophysiological recordings, analysis of data, and statistical comparisons were blind to treatment schedules (i.e., the experimenter was unaware of the animal's group assignment). A simple randomization procedure was used to assign mice to either vehicle or psychostimulant treatment.

\section{Psychostimulants administration}

A simple randomization procedure was used to assign mice to either vehicle or psychostimulant treatments. Cocaine hydrochloride and caffeine (Sigma-Aldrich, St Louis, MO) were administered in a binge-like regimen of three i.p. injections per day, $1 \mathrm{~h}$ apart, following an intermittent protocol of administration, i.e., mice received binge injections during either 1 day (acute) or 1 day on/1 day off during 13 days for a total of 7 binges (chronic) (Muñiz et al. 2016, 2017). Animals were randomly assigned to four different groups: cocaine $(\mathrm{Coc}, 3 \times$ $10 \mathrm{mg} / \mathrm{kg}$ ), caffeine (Caf, $3 \times 5 \mathrm{mg} / \mathrm{kg}), \mathrm{Coc}+\mathrm{Caf}(3 \times$ Cocaine+Caffeine combined solution: Coc $10 \mathrm{mg} / \mathrm{kg}+\mathrm{Caf}$ $5 \mathrm{mg} / \mathrm{kg}$, both dissolved in the same sterile saline solution and co-administered in a single injection), or Veh $(3 \times$ saline $)$.

\section{Thalamocortical slices and whole-cell patch-clamp recordings}

Slices were obtained $24 \mathrm{~h}$ after the last injection of either acute or chronic protocol (Urbano et al. 2009; Bisagno et al. 2010; Goitia et al. 2013, 2016; Perissinotti et al. 2018). Mice were deeply anesthetized with tribromoethanol $(250 \mathrm{mg} / \mathrm{kg}$; i.p. $)$ followed by transcardial perfusion with ice-cold low sodium/ antioxidant solution (composition in mM: 200 sucrose, 2.5 $\mathrm{KCl}, 3 \mathrm{MgSO}_{4}, 26 \mathrm{NaHCO}_{3}, 1.25 \mathrm{NaH}_{2} \mathrm{PO}_{4}, 20 \mathrm{D}$-glucose, 0.4 ascorbic acid, 2 pyruvic acid, 1 kynurenic acid, $1 \mathrm{CaCl}_{2}$,

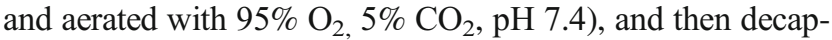
itated. Thalamocortical brain slices $(300 \mu \mathrm{m})$ were obtained by gluing both hemispheres onto a vibratome stage (PELCO, EasiSlicer, Ted Pella Inc., CA, USA), submerged in a chamber containing chilled low-sodium/high-sucrose solution (composition in mM: 250 sucrose, $2.5 \mathrm{KCl}, 3 \mathrm{MgSO}_{4}, 0.1$ $\mathrm{CaCl}_{2}, 1.25 \mathrm{NaH}_{2} \mathrm{PO}_{4}, 0.4$ ascorbic acid, 3 myo-inositol, 2 pyruvic acid, $25 \mathrm{D}$-glucose, and $25 \mathrm{NaHCO}_{3}$ ). Slices were cut sequentially and transferred to an incubation chamber at $35^{\circ} \mathrm{C}$ for 30 min containing a stimulant-free, low $\mathrm{Ca}^{2+} / \mathrm{high}$ $\mathrm{Mg}^{2+}$ normal artificial cerebrospinal fluid (ACSF) (composition in mM: $125 \mathrm{NaCl}, 2.5 \mathrm{KCl}, 3 \mathrm{MgSO}_{4}, 0.1 \mathrm{CaCl}_{2}, 1.25$ $\mathrm{NaH}_{2} \mathrm{PO}_{4}, 0.4$ ascorbic acid, 3 myo-inositol, 2 pyruvic acid, $25 \mathrm{~d}$-glucose, and $25 \mathrm{NaHCO}_{3}$ and aerated with $95 \% \mathrm{O}_{2} / 5 \%$ $\mathrm{CO}_{2}, \mathrm{pH}$ 7.4).

Whole-cell patch-clamp recordings of ventrobasal (VB) thalamocortical neurons were performed at room temperature $\left(20-24{ }^{\circ} \mathrm{C}\right)$ in normal ACSF with $\mathrm{MgCl}_{2}(1 \mathrm{mM})$ and $\mathrm{CaCl}_{2}$ ( $2 \mathrm{mM})$. Patch electrodes were made from borosilicate glass (2-3 M $\Omega$ ) filled with either high $\mathrm{K}^{+}$solution (composition in mM: 110 potassium gluconate, $30 \mathrm{KCl}, 10 \mathrm{HEPES}, 10 \mathrm{Na}_{2}$ phosphocreatine, 0.2 EGTA, 2 Mg-ATP 2, 0.5 Li-GTP, and 1 $\mathrm{MgCl}_{2} ; \mathrm{pH}$ was adjusted to 7.3 with $\mathrm{KOH}$ ) or high $\mathrm{Cl}^{-}$, high $\mathrm{Cs}^{+} / \mathrm{QX} 314$ solution (composition in $\mathrm{mM}: 110 \mathrm{CsCl}, 40$ HEPES, 10 TEA-Cl, $12 \mathrm{Na}_{2}$ phosphocreatine, 0.5 EGTA, $2 \mathrm{Mg}$-ATP, $0.5 \mathrm{Li}$-GTP, and $1 \mathrm{MgCl}_{2}$. $\mathrm{pH}$ was adjusted to 7.3 with $\mathrm{CsOH}$ ). When needed, voltage-dependent $\mathrm{Na}^{+}$ currents/postsynaptic action potentials were blocked using $10 \mathrm{mM} \mathrm{N}$-(2,6-diethylphenylcarbamoylmethyl) triethylammonium chloride (QX-314) in the intracellular solution. Signals were recorded using a MultiClamp 700 amplifier commanded by pCLAMP 10.0 software (Molecular Devices, CA, USA). Data were filtered at $5 \mathrm{kHz}$, digitized, and stored for off-line analysis.

Cell capacitance was measured from a transient current evoked by a $5-\mathrm{mV}$ depolarizing step from a holding potential of $-90 \mathrm{mV}$. Cells with series resistance (Rs) $<15 \mathrm{M} \Omega$ were used after being compensated online $(>80 \%)$.

\section{Hyperpolarization-activated cyclic nucleotide-gated (HCN)-mediated currents}

Hyperpolarization-activated cyclic nucleotide-gated $(\mathrm{HCN})$ or H-currents $\left(\mathrm{I}_{\mathrm{H}}\right)$ were studied in "voltage-clamp" mode using a K-Gluconate intracellular solution. $\mathrm{I}_{\mathrm{H}}$ is a nonspecific cationic current that is activated by hyperpolarization of the membrane and was pharmacologically isolated using specific blockers for voltage-gated sodium channels (TTX $3 \mu \mathrm{M}$ ), potassium channels (TEA; $10 \mathrm{mM}, \mathrm{BaCl}_{2} ; 0.5 \mathrm{mM}$ ), calcium channels $\left(\mathrm{CdCl}_{2} ; 0.1 \mathrm{mM}\right.$ ), and glutamate receptors NMDA (AP-5 $50 \mu \mathrm{M})$ and AMPA (CNQX; $20 \mu \mathrm{M})$, plus GABA-A receptors (Bicuculline; $50 \mu \mathrm{M}$ ). In order to identify $\mathrm{I}_{\mathrm{H}}$, the specific blocker for it was used ZD7288 (30 $\mu \mathrm{M})$ (Lüthi et al. 1998; Zhang et al. 2016). Once $\mathrm{I}_{\mathrm{H}}$ current was identified, a protocol was implemented in order to increase the stability of the 
registers in the "voltage-clamp" mode, as well as to account for its increasing activation speed (Kanyshkova et al. 2009). $\mathrm{I}_{\mathrm{H}}$ steady-state activation (SSA) was estimated by normalizing the tail current amplitudes measured $50 \mathrm{~ms}$ after a variable prepulse holding potential (from -40 to $-130 \mathrm{mV}$ ) to a fixed holding potential of $-100 \mathrm{mV}$. The following equation was used in order to fit SSA:

$$
V=\left(I_{(V)}-I_{\min }\right) /\left(I_{\max }-I_{\min }\right),
$$

where $I_{\max }$ being the amplitude of the tail current for the voltage step from -130 to $-100 \mathrm{mV}$ and $\mathrm{I}_{\min }$ for the voltage step from -40 to $-100 \mathrm{mV}$. $\mathrm{I}_{\mathrm{H}}$ activation was fitted to the Boltzmann equation:

$I / I_{\max }=1 /\left(1+\exp \left(\left(\mathrm{V}-\mathrm{V}_{50}\right) / \mathrm{k}\right)\right.$

where $V$ is the membrane potential of the prepulse, $V_{50}$ is the membrane potential in which half of $\mathrm{I}_{\mathrm{H}}$ is activated, and $k$ is the slope or "slow factor" (Momin et al. 2008).

\section{Biophysical parameters of T-type calcium currents and low-threshold spikes}

T-type voltage-gated calcium currents $\left(\mathrm{I}_{\mathrm{T}}\right)$ were generated in voltage-clamp using an intracellular solution based on high $\mathrm{Cl}^{-}$, high $\mathrm{Cs}^{+} / \mathrm{QX}-314$. $\mathrm{I}_{\mathrm{T}}$ was pharmacologically isolated adding the following specific blockers to ACSF: TTX $(3 \mu \mathrm{M})$, TEA $(10 \mathrm{mM})$, DL-AP-5 $(50 \mu \mathrm{M})$, CNQX $(20 \mu \mathrm{M})$, Bicucullin $(50 \mu \mathrm{M})$. Voltage dependence of $\mathrm{I}_{\mathrm{T}}$ was studied using square pulses initially to hyperpolarizing holding potentials to de-inactivate T-type channels, followed by depolarizing holding pulses (Perissinotti et al. 2014). Hyperpolarization time and depolarizing pulses varied between experiments. T-type current conductance was calculated using an I-V protocol of depolarizing voltage holding steps from -110 to $-45 \mathrm{mV}$ in $5 \mathrm{mV}$ steps. For each voltage step applied, the conductance $\mathrm{G}\left(\mathrm{V}_{\mathrm{H}}\right)=\mathrm{I}_{\mathrm{T}}\left(\mathrm{V}_{\mathrm{H}}\right) /\left(\mathrm{V}_{\mathrm{H}}-40 \mathrm{mV}\right)$ was calculated, where $\mathrm{I}_{\mathrm{T}}$ is the current activated by the voltage holding $\left(\mathrm{V}_{\mathrm{H}}\right)$ and $40 \mathrm{mV}$ is the estimated reversal potential for calcium. To determine the voltage dependence of the fraction of channels available to be activated, a "steady-state inactivation" (SSI) protocol was used (Perissinotti et al. 2014): pre-pulse, holding potential was brought from -110 to $45 \mathrm{mV}$ in $5 \mathrm{mV}$ steps, during $500 \mathrm{~ms}$ to de-inactivate T-type channels. Test pulse, the fraction of T-type channels available were tested at a single step to a holding of $-50 \mathrm{mV}$. $\mathrm{I}_{\mathrm{T}} / \mathrm{I}_{\mathrm{T}}$ max ratio was plotted as a function of holding potential $\left(\mathrm{V}_{\mathrm{H}}\right)$.

Both activation and inactivation curves for $\mathrm{I}_{\mathrm{T}}$ were fitted to a Boltzmann equation:

Activation curve, $\mathrm{G} / \mathrm{G}_{\max }=1 /\left(1+\exp \left(\mathrm{v}_{\mathrm{H}}-\mathrm{v}_{50}\right) / \mathrm{k}\right)$
Inactivation curve, $I_{T} / I_{T}, \max =1 /\left(1+\exp \left(\mathrm{v}_{\mathrm{H}}-\mathrm{V}_{50}\right) / \mathrm{k}\right)$

where $G$ is the conductance for each holding potential pulse, and $G_{\max }$ the maximum conductance. $\mathrm{I}_{\mathrm{T}} / \mathrm{I}_{\mathrm{T}}$, max is the available fraction of $\mathrm{T}$ channels and its dependence on voltage represents the inactivation curve. $\mathrm{V}_{50}$ represents the voltage at which $50 \%$ of the total population of channels was activated/inactivated, respectively; $\mathrm{k}$ is a slope factor indicating $\mathrm{I}_{\mathrm{T}}$ currents voltage-dependence. We've used the following equation to calculate the theoretical "Window current" (i.e., the overlapping section after fitting to a Boltzmann equation both activation and inactivation curves):

$\mathrm{I}_{\mathrm{T}}(\mathrm{stst})=\mathrm{G}\left(\mathrm{V}_{\mathrm{H}}\right) * \mathrm{I}_{\mathrm{T}} / \mathrm{I}_{\mathrm{T}, \max }\left(\mathrm{V}_{\mathrm{H}}\right) *\left(\mathrm{~V}_{\mathrm{H}}-40 \mathrm{mV}\right)$

where $\mathrm{I}_{\mathrm{T}}$ (stst) is the current in the steady-state or "window current," $\mathrm{G}$ is the conductance at holding voltage $\mathrm{V}_{\mathrm{H}}, \mathrm{I}_{\mathrm{T}} / \mathrm{I}_{\mathrm{T} \text {,max }}$ is the fraction of T-type channels available at holding voltage $\mathrm{V}_{\mathrm{H}}$, and $40 \mathrm{mV}$ is the estimated reversal potential for calcium. Reversal potential for $\mathrm{Ca}^{2+}$ ions $\left(\mathrm{E}_{\mathrm{Ca}}\right)$ was calculated using average currentvoltage (I-V) curves from holding current pulses $(n=$ $16)$ or current ramps $(n=13)$ during VB recordings.

\section{Current-clamp experiments}

Current-clamp experiments were performed using a KGluconate intracellular solution. No spontaneous action potential (AP) discharge was observed at resting membrane potential during whole-cell recordings of VB thalamocortical neurons.

Resting membrane potential (RMP) was recorded in continuous trace mode without current injection for $20 \mathrm{~s}$, and averaged; voltages were corrected for liquid junction potentials.

Whole cell input resistance $\left(\mathrm{R}_{\text {in }}\right)$ was determined as the slope obtained from instantaneous voltage-current relationships (V-I curves). V-I curves were constructed using current steps progressing at $100 \mathrm{pA}$ increments, starting from -500 to $100 \mathrm{pA}$ (500 ms duration).

Low-threshold spikes (LTS) were generated using a hyperpolarizing current pulse of -100 or $-200 \mathrm{pA}$ for $500 \mathrm{~ms}$.

Membrane excitability was calculated after applying an hyperpolarizing current step (-200 pA for $50 \mathrm{~ms})$, AP discharges were elicited by injection of a depolarizing current ramp (from -200 to $800 \mathrm{pA}$ during $1.5 \mathrm{~s}$, ramp rate $=667 \mathrm{pA} / \mathrm{s}$ ). The membrane potential was held at $-65 \mathrm{mV}\left(\mathrm{V}_{\mathrm{H}}\right)$. The action potential voltage threshold was determined using the first derivative of the first AP. 


\section{Ratiometric calcium imaging}

$\mathrm{Ca}^{2+}$-imaging in VB neurons was performed concurrently with whole-cell recordings using an Andor iXon+ EMCCD camera $(512 \times 512$, Andor tech., Belfast, UK) coupled to a monochromator Polychrome V (TILL Photonics GmbH, Munich, Germany) through an optic fiber connected to a BX51WI Olympus upright microscope (Olympus Latin America Inc., FL, USA). To allow sufficient intarcellular filling of VB neurons with dye, imaging was initiated 5-10 min after obtaining whole-cell configuration. The ratiometric $\mathrm{Ca}^{2+}$-sensitive indicator fura-2 (in vitro $\mathrm{K}_{\mathrm{d}}=224 \mathrm{nM}$ ) allowed a more accurate report of the time course and amplitude of intracellular $\left[\mathrm{Ca}^{2+}\right]$ dynamics at somatic and proximal dendrites level (Rozas et al. 2017). Fluorescence changes at $510 \mathrm{~nm}$ were acquired after consecutive $340 \mathrm{~nm}$ and $380 \mathrm{~nm}$ wavelengths using a 0.8 numerical aperture water-immersion 40× objective (Olympus Latin America Inc., FL, USA). Image acquisition was performed using cell-R software (Olympus Soft Imaging Solutions, Münster, Germany), and analyzed post hoc using NIH Image J software. Imaging protocol consisted of 50 images (130 ms exposition time) to calculate background fluorescence prior to a hyperpolarizing current pulse of $-200 \mathrm{pA}$ of $500 \mathrm{~ms}$ duration in current-clamp using a K-Gluconate intracellular solution. Then, 150 images were taken after hyperpolarizing current pulse. Fluorescence ratio $\left(\mathrm{F}_{340} / \mathrm{F}_{380}\right)$ was estimated offline to intracellular $\mathrm{Ca}^{2+}$ concentration $\left(\left[\mathrm{Ca}^{2+}\right]_{\mathrm{i}}\right)$ using a calibration curve (Rankovic et al. 2010; Di Guilmi et al. 2014). No dye saturation was appreciated during analysis of experiments that used current injection of hyperpolarizing pulses. However, Rmax is the highest ratio value obtained when Fura-2 is saturated following previously described protocols (Usachev et al. 1993; Rankovic et al. 2010; Di Guilmi et al. 2014). $R_{\min }$ was the minimum ratio obtained in the absence of calcium (Usachev et al. 1993; Rankovic et al. 2010; Di Guilmi et al. 2014).

\section{Electroencephalography/electromyography recordings}

Mice were deeply anesthetized on a thermal blanket $\left(36^{\circ} \mathrm{C}\right)$ using a gaseous mixture of isoflurane $\left(2 \%\right.$ in $\left.\mathrm{O}_{2}\right)$ and placed in a stereotaxic frame. After exposing the skull, four electroencephalography (EEG) recording screws with attached wires (0.10" screw with wire leads, Part \#8403, Pinnacle Technology, Inc., Lawrence, KS) were placed contralaterally across the somatosensory/motor cortex, ground electrode between preculminate and primary fissure, cerebellum, while electromyography (EMG) connectors were inserted into the nuchal muscles. All electrode leads were connected to a head mount (Part \#8201, 6 pins, $8 \times 5$ mm, Pinnacle Technology, Inc.) and sealed with dental acrylic HydroC (Dentsply, Buenos Aires, Argentina). While anesthetized, mice received subcutaneously one dose of antibiotic (enrofloxacin, 85 $\mathrm{mg} / \mathrm{kg}$; John Martin Inc., Argentina) co-injected with analgesic (meloxicam, $5 \mathrm{mg} / \mathrm{kg}$; John Martin Inc., Argentina). After surgeries, mice were administered with analgesic (tramadol, $20 \mathrm{mg} / \mathrm{ml}$; Panacea Inc., Argentina) in their drinking water bottle. No changes in animal weights were observed from the day electrodes were implanted until the last day of EEG/ EMG recordings (Table 1).

From day 14 post-surgery, each implanted animal was placed in the acrylic cylinder for habituation to the registration arena for periods of $2-4 \mathrm{~h}$ per day in the presence of ad libitum food and water. One week after the habituation period, the animals were placed in the acrylic cylinder at $15-16 \mathrm{~h}$. On the day of registration, connecting them to the pre-amplifier unit (Part \# 8202-SL, Pinnacle Technology, Inc.) rigidly attached to the mouse head mount provided 1st-stage amplification $(100 \times)$ and initial high-pass filtering (1st-order $0.5 \mathrm{~Hz}$ for EEG and $10 \mathrm{~Hz}$ for EMG). All signals were routed to the conditioning/acquisition system (Data Conditioning \& Acquisition System \# 8206, Pinnacle Technology, Inc.) via a tether and low-torque commutator. Recording signals were further fifty-fold amplified, additional high-pass filtering, and an 8th order elliptic low-pass filter (50 Hz EEG and $200 \mathrm{~Hz}$ EMG). The signals were then sampled at $200 \mathrm{~Hz}$, digitized using a 14-bit analog to digital converter and routed to a PC-based acquisition and analysis software package via USB. During offline analysis, awake stage was characterized by a preponderance of low amplitude, high frequency signals in the EEG signals combination with a highly variable muscle tone from electrodes inserted into the animal's neck (EMG). It was common to simultaneously observe abundant muscle activity on the EMG. During REM sleep clear peaks at thetaband frequencies $(\theta, 5-8 \mathrm{~Hz})$ with no EMG activity were recorded. No REM sleep stage was characterized by unchanging muscle-related EMG activity and high power activity at low frequency bands, as $\delta$-band $[0.1-3.5 \mathrm{~Hz}]$.

\section{Statistical analysis and data presentation}

Data were stored for off-line analysis using Clampfit (pCLAMP 10.0, Molecular Devices, CA, USA). Comparisons between groups were carried out using OriginPro 9.1.0 (Origin lab.com, MA, USA). Normality and equal variance test were performed prior to ANOVA comparisons using Origin Pro 9.1.0. No sample calculation was performed. Data is presented as mean \pm standard error of the mean. Data values that showed more/less than two times the standard deviation from the mean were excluded. Statistics were performed using $t$ test, ANOVA, RM ANOVA, and nonparametrics test (Mann-Whitney Rank Sum Test and KruskalWallis ANOVA on Ranks) when applicable. LSD Fisher's, Holm-Sidak's, or Tukey test's post hoc test were used to test statistical significance. Number of cells recorded is shown 
Table 1 Animal weight from the day electrodes were implanted until the last day of EEG/EMG recordings

\begin{tabular}{lllll}
\hline & Day 1: implanting electrodes & Day 14 & Day 21 & Day 30 \\
\hline Animal weight (gr.) & $31 \pm 1.2(9)$ & $31 \pm 0.8(9)$ & $31 \pm 0.9(9)$ & $32 \pm 0.9(9)$ \\
\hline
\end{tabular}

No significant differences were found comparing the weights of the animals throughout the experiment (one-way ANOVA; $\left.F_{(3.32)}=0.1, p=0.9\right)$ throughout the text as " $\mathrm{n}=$." Differences were considered significant if $p<0.05$.

\section{Drugs and toxins}

TTX was purchase from Alomone Labs. (Israel). Bicuculline, caffeine, cocaine, CNQX, DL-AP5, TEA, and salts used were purchased from Sigma-Aldrich (Argentina).

\section{Results}

Psychostimulant administration schedule and doses used in this work were based on previous studies published by our research group (Muñiz et al. 2016, 2017). Mice were injected with a mixture of cocaine and caffeine (PACO-like binge), whose composition resembles previously analyzed "cocaine pasta base" samples (Coc $10 \mathrm{mg} / \mathrm{kg}$ + Caf $5 \mathrm{mg} / \mathrm{kg}$; see Muñiz et al. 2016, 2017). In addition, separate administrations of caffeine $(5 \mathrm{mg} / \mathrm{kg})$ or cocaine $(10 \mathrm{mg} / \mathrm{kg})$ were performed to elucidate the effects of their combination. Psychostimulants were administered in a binge-like form (i.e., three injections, $1 \mathrm{~h}$ apart) following an acute or chronic protocol (see Materials a Methods).

\section{Characterization of both H-type and T-type currents in thalamocortical ventrobasal neurons 24-h after acute binge treatments}

We studied $\mathrm{H}$ and and $\mathrm{T}$-type currents $\left(\mathrm{I}_{\mathrm{H}}, \mathrm{I}_{\mathrm{T}}\right)$ in ventrobasal ThCo neurons 24-h after the acute administration of psychostimulants: saline (control), cocaine + caffeine ("PACO"-like binge), cocaine, and caffeine (Fig. 1).

$\mathrm{I}_{\mathrm{H}}$ was pharmacologically isolated as described in Materials and Methods. $\mathrm{I}_{\mathrm{H}}$ elicited by a hyperpolarizing pulse from -40 to $-100 \mathrm{mV}$ was markedly suppressed by its specific channel blocker ZD7288 (Fig. 1a). Characterization of activating and deactivating $\mathrm{I}_{\mathrm{H}}$ currents revealed that an acute "PACO"-like binge was associated with a significant increase of the $\mathrm{I}_{\mathrm{H}}$ current density (two-way RM ANOVA, $p<0.05$ ), whereas the voltage-dependency of activation remained unaltered (Fig. $1 \mathrm{~b}$ and c). Activation kinetics were best fitted by a double-exponential function and revealed no changes (not shown). However, a cocaine binge also increased $\mathrm{I}_{\mathrm{H}}$, whereas a caffeine binge did not produced any effect (ANOVA, $p<0.05$, Fig. 1d). Similarly, Urbano et al. (2009) reported an increase of $\mathrm{I}_{\mathrm{H}}$ in VB neurons $1 \mathrm{~h}$ after an acute binge of cocaine. Therefore, $\mathrm{I}_{\mathrm{H}}$ alteration observed 24-h after an acute "PACO"-like binge could be atribuited to cocaine effects.

$\mathrm{I}_{\mathrm{T}}$ was pharmacologically isolated as described in the "Materials and Methods" section. $\mathrm{I}_{\mathrm{T}}$ elicited by a depolarizing pulse from -100 to $-40 \mathrm{mV}$ was blocked by its specific channel blocker TTA-A2 (Fig. 1e). Analysis of currentvoltage relationship (I-V curves) showed that the $\mathrm{I}_{T}$ current density was not affected 24-h after an acute "PACO"-like binge (Fig. 1f and g). However, both cocaine and caffeine binges (separately administrations) increased the $\mathrm{I}_{\mathrm{T}}$ current density (ANOVA, $p<0.05$, Fig. 1h). Similarly, Urbano et al. (2009) reported an increase of $I_{T}$ in VB neurons 1 and 24-h after an acute binge of cocaine. Our results suggested that the combined administration of cocaine and caffeine ("PACO"-like binge) prevented the increase of $\mathrm{I}_{\mathrm{T}}$ that was observed in separately administrations of cocaine or caffeine.

$\mathrm{HCN}$ channels have been described to interact with T-type calcium channels (Fan et al. 2017) and they are key channels modulating the resting membrane potential (RMP) in thalamocortical neurons (Meuth et al. 2006; Budde et al. 2008). Figure 2a shows that the RMP was depolarized by $10 \mathrm{mV}$ after PACO-like and cocaine binges (ANOVA, $p<0.05$ ), according to the observed increase of $\mathrm{I}_{\mathrm{H}}$ current density.

Activation/deactivation dynamic of $\mathrm{I}_{\mathrm{H}}$ intertwined with $\mathrm{T}$ type calcium channels activation after membrane potential hyperpolarization (Jahnsen and Llinás 1984a, b), modulating the amplitudes and duration of low-threshold spikes (LTS). In order to study the functional interaction between $\mathrm{I}_{\mathrm{H}}$ and $\mathrm{I}_{\mathrm{T}}$, we used a rebound protocol ( -100 or $-200 \mathrm{pA}$ for $500 \mathrm{~ms})$. LTS refer to large membrane depolarizations mediated by an increase of T-type calcium conductance, T-type channels open when the membrane potential is released from hyperpolarization at the end of a current step, as seen in VB neurons recorded under current clamp recording mode (Fig. 2b). The steady hyperpolarization current step also revealed the activation of $\mathrm{I}_{\mathrm{H}}$ current that underlied a "sag" in the voltage response of VB neurons (Fig. 2b). Note how in the presence of $\mathrm{Ni}^{2+}$, an unsmask component related to $\mathrm{I}_{\mathrm{H}}$ current-deactivation also contributes to rebound bursting (Fig. 2b). As seen in Fig. 2c, the specific blocker ZD7288 of $\mathrm{I}_{\mathrm{H}}$ prevented this "sag" formation and delayed the LTS response. Upon release from membrane hyperpolarization, the averaged amplitude of LTS in VB neurons was larger after an acute "PACO"-like binge in comparison to other treatments (ANOVA, $p<0.05$, Fig. $2 \mathrm{~d}$ 
and e). These results suggested that, in response to a hyperpolarizing input, VB neurons solely exhibit increased T-type calcium-mediated, low-threshold spike (LTS) amplitudes when cocaine was administered in combination with caffeine.

\section{Acute "PACO"-like binge administration alters biophysical properties of T-type voltage-gated calci- um channels}

So far, our results suggest that acute "PACO"-like binge administrations prevented the increase of $\mathrm{I}_{\mathrm{T}}$ that was observed after separately administrations of cocaine or caffeine (Fig. 1f-H). However, upon release from membrane hyperpolarization, only VB neurons that underwent an acute "PACO"-like binge treatment exhibited an increase of LTS amplitudes (Fig. 2). Therefore, we studied voltage and time dependence of Ttype voltage-gated calcium currents in VB neurons comparing control vs. "PACO"-like binge acute treatments.

The voltage-dependent activation of $\mathrm{I}_{\mathrm{T}}$ was determined by hyperpolarizing the holding potential to $-110 \mathrm{mV}$ for $500 \mathrm{~ms}$ and then progressing in $5 \mathrm{mV}$ depolarizing steps towards $\mathrm{T}$ type channels activation, as shown normalized current traces $\left(\mathrm{I} / \mathrm{I}_{\max }\right)$ depicted in Fig. 3a. Peak current conductance for each holding step was normalized to the maximally elicited current conductance $\left(\mathrm{G} / \mathrm{G}_{\max }\right)$ represented steady-state activation (SSA) of $\mathrm{I}_{\mathrm{T}}$ for control (black dots) and "PACO"-like binge (red dots) treatments. Average values were plotted against its respective holding pulse potential and fitted using a Boltzmann equation (Fig. 3b). The $\mathrm{V}_{50}$ parameter was $-65.2 \pm 1.5 \mathrm{mV}$ $(n=10)$ in control compared to $-60.7 \pm 1.7 \mathrm{mV}(n=6)$ after a "PACO"-like binge treatment. In addition, the slope factor $k$ increased after a "PACO"-like binge $(2.3 \pm 0.2 \mathrm{mV}$ vs. $4.0 \pm$ $0.5 \mathrm{mV}$ ). SSA curves analysis showed that its midpoint potential $\left(\mathrm{V}_{50}\right)$ was significantly shifted by about $\sim 5 \mathrm{mV}$ after a "PACO"-like binge compared to control (Student's $t$ test, $\left.\mathrm{t}_{14}=-1.94, p<0.05\right)$. The approximate RMP for control $(\sim$ $-70 \mathrm{mV}$, black symbols/lines) and "PACO"-like binge ( $60 \mathrm{mV}$, red symbols/lines) groups are shown on the voltage axis of Fig. 3b. Thin lines showed interpolating RMP values towards $\mathrm{Y}$-axis, obtaining the activable fraction of deinactivated $\mathrm{I}_{\mathrm{T}}$. In control conditions (black line), a $\sim 0.25$ fraction of $\mathrm{I}_{\mathrm{T}}$ would be activated at holding potentials within close range to resting membrane potentials. However, after acute "PACO"-like binges, a $\sim 0.55$ fraction of $\mathrm{I}_{\mathrm{T}}$ would be activated at observed resting membrane potential values.

The steady-state inactivation (SSI) of the T-type $\mathrm{Ca}^{2+}$ current was determined by hyperpolarizing command potentials progressing at $-5 \mathrm{mV}$ increments, starting from -45 to $110 \mathrm{mV}$ pre-pulse potentials for $500 \mathrm{~ms}$ and then stepping to the test potential $(-50 \mathrm{mV})$. Peak currents for each step were normalized to the maximally elicited currents $\left(\mathrm{I} / \mathrm{I}_{\max }\right.$, Fig. $\left.3 \mathrm{c}\right)$ and average values were plotted against its respective prepulse holding potential for control (black dots) and
"PACO"-like binge treatment (red dots) (Fig. 3d). The inactivation data was fitted to a Boltzmann equation. The SSI $\mathrm{V}_{50}$ value changed from $-85.5 \pm 1.4 \mathrm{mV}(n=11)$ in controls to $78.7 \pm 1.0 \mathrm{mV}(n=6)$ after "PACO"-like binges; no change in the slope factor $k$ was observed $(-5.3 \pm 0.3 \mathrm{mV}$ vs. $-5.6 \pm$ $0.4 \mathrm{mV})$. The SSI midpoint potential $\left(\mathrm{V}_{50}\right)$ was significantly shifted by about $\sim 7 \mathrm{mV}$ after a "PACO"-like binge compared to control (Student's $t$ test, $\mathrm{t}_{15}=-3.2, p<0.05$ ). The observed depolarizing shift between steady-state inactivation curves suggested an increment in the T-type $\mathrm{Ca}^{2+}$ channel availability. Thus, we concluded that an acute "PACO"-like binge increased the fraction of deinactivated T-type $\mathrm{Ca}^{2+}$ channels (i.e., availability) near resting membrane potentials. For instance, a depolarizing step from a holding potential of $110 \mathrm{mV}$ in which all T-type $\mathrm{Ca}^{2+}$ channels were fully deinactivated (see orange bar showed on the left, Fig. 3d) showed no changes in $\mathrm{I}_{\mathrm{T}}$ current density between control and "PACO"-like binge treatments (Fig. 3e). However, average $\mathrm{I}_{\mathrm{T}}$ current density elicited from a holding potential of $70 \mathrm{mV}$ were 3 -fold bigger after a "PACO"-like binge (Fig. $3 e$ ), as expected according to the shift in the steady-state inactivation observed in Fig. $3 \mathrm{~d}$ (see the fraction of deinactivated channels indicated by the light blue bar).

Overall, our results suggested that after an acute "PACO"like binge, a larger fraction of T-type $\mathrm{Ca}^{2+}$ channels would be deinactivated after membrane hyperpolarization by an inhibitory input in comparison to control (i.e., a "PACO"-like binge increases the availability of T-type $\mathrm{Ca}^{2+}$ channels, Fig. $3 \mathrm{c}$ and d). In addition, the depolarizing effect of a "PACO"-like binge on the RMP would increase the activable fraction of deinactivated T-type channels when the membrane potential suddenly reached its resting value at the end of the inhibitory input (Fig. 3a and b), favoring the generation of large LTSassociated $\mathrm{Ca}^{2+}$ transients, as shown above on Fig. 2 (d and e).

T-type $\mathrm{Ca}^{2+}$ channels operate in a subthreshold voltage range, with an overlap between activation and steady-state inactivation curves that produces a voltage range where a subset of T-type channels is constitutively active (i.e., steady-state current, $\mathrm{I}_{\text {stst }}$ or "window current") (Hughes et al. 1999; Crunelli et al. 2005). Such "window current" can be observed as the "shaded region" underneath the activation and steadystate inactivation curves, which was shifted towards depolarizing potentials after an acute "PACO"-like binge (Fig. 3f, inset). The "window current" was theoretically estimated using the fitting parameters of the steady-state inactivation and activation curves (see "Material and Methods") (Bijlenga et al. 2000; Lambert et al. 2014). The amplitude of the "window current" after an acute "PACO"-like binge was $\sim 3$ times larger than the control (Fig. $3 \mathrm{f}$ and $\mathrm{g}-\mathrm{I}_{\text {peak }}$ ). Moreover, the range of its voltage dependency was broader than the control (Fig. 3f, G- $\Delta \mathrm{V}_{50}$ ). Boxplots in Fig. 3f depict the RMP for both control and "PACO"-like binge treatments. Interestingly, the "window current" increased $~ 3-4$ times at 
a

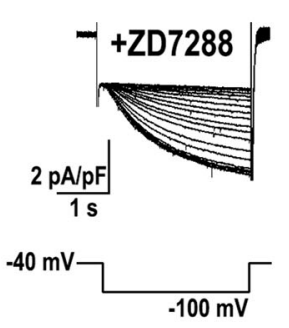

C

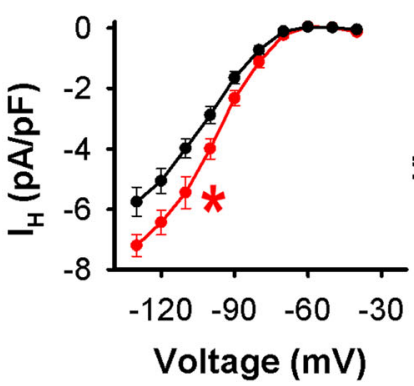

$\because$ Control

e

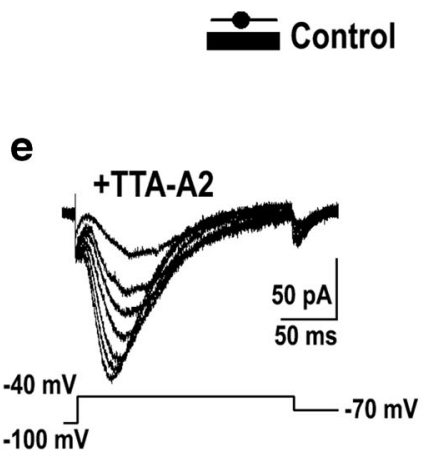

b

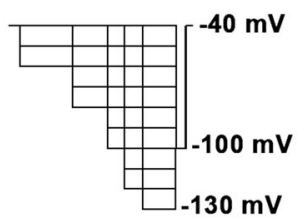

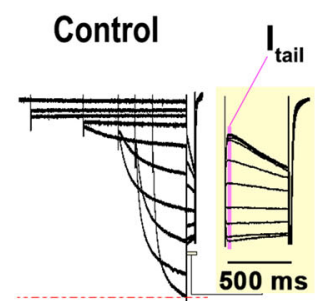

"PACO"-like binge

(Cocaine+Caffeine)

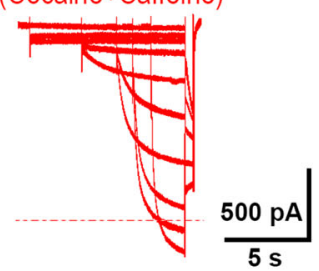

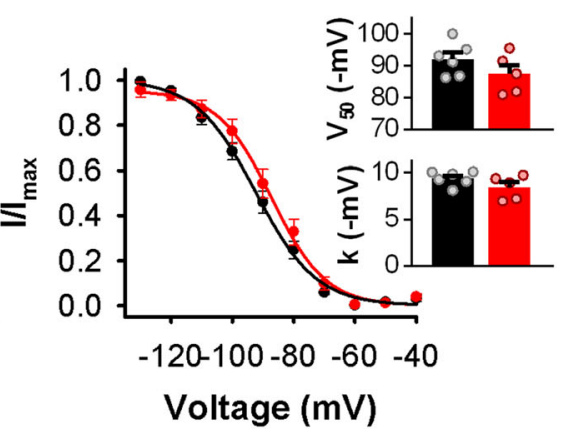

d

d 0

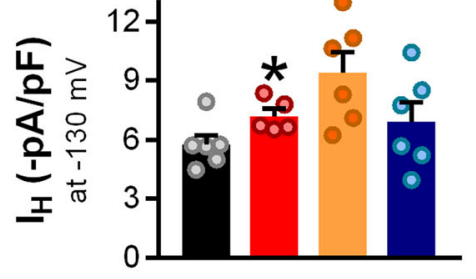

g

Voltage $(\mathrm{mV})$

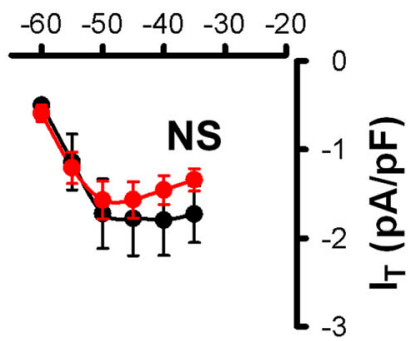

the RMP after an acute "PACO"-like binge compared to control. Therefore, after an acute "PACO"-like binge, a large subset of T-type $\mathrm{Ca}^{2+}$ channels should be constitutively active at RMP compared to control, leading to a stationary $\mathrm{Ca}^{2+}$ influx and a persistent enhancement of $\left[\mathrm{Ca}^{2+}\right]_{i}$.

\section{Acute "PACO"-like binge administration alters intracellular calcium dynamics}

To further confirm our findings, we investigated whether acute "PACO"-like binges lead to detectable changes in intracellular $\mathrm{Ca}^{2+}$ concentration. Ratiometric Fura-2-based calcium imaging was performed concurrently with wholecell recordings in VB neurons (Di Guilmi et al. 2014; Rozas et al. 2017; Rankovic et al. 2010). We determined the basal $\left[\mathrm{Ca}^{2+}\right]_{\mathrm{i}}$ and used an inhibitory current step $(-200 \mathrm{pA}$ for $500 \mathrm{~ms}$ ) to measure $\mathrm{Ca}^{2+}$ transients (LTS) associated to $\mathrm{H}$ and T-type currents (Fig. 4a). We used a K-gluconate/EGTA free intracellular solution in current-clamp configuration and an artificial cerebrospinal fluid (ACSF) with TTX, TEA, and synaptic blockers (AP5, CNQX, and bicuculline) to preclude the activation of voltage-gated sodium and potassium 
4 Fig. 1 Characterizarion of $\mathrm{H}$ and T-type currents 24-h after acute binge treatments in thalamocortical ventrobasal neurons. a Blocking effect of an $\mathrm{HCN}$ specific blocker, ZD7288 $(30 \mu \mathrm{M})$. HCN-mediated current $\left(\mathrm{I}_{\mathrm{H}}\right)$ was evoked by an hiperpolarizing voltage step from a holding potential $\left(\mathrm{V}_{\mathrm{H}}\right)$ of -40 to $-100 \mathrm{mV}$ (in an ACSF $+3 \mu \mathrm{M}$ TTX, $10 \mathrm{mM}$ TEA, $0.5 \mathrm{mM}$ $\mathrm{BaCl}_{2}, 0.1 \mathrm{mM} \mathrm{CdCl} 2,50 \mu \mathrm{M}$ DL-AP-5, $20 \mu \mathrm{M} \mathrm{CNQX}, 50 \mu \mathrm{M}$ Bicuculline). Current traces show time course of ZD7288 bath application(1 trace/min), reaching its maximum blocking effect after 13 min. b $\mathrm{I}_{\mathrm{H}}$ activation protocol (left plot) comparing VB neurons from control (center plot) vs. "PACO"-like binge treated mice (right plot), using a protocol that changed $\mathrm{V}_{\mathrm{H}}$ from -40 to $-130 \mathrm{mV}$, at $10 \mathrm{mV}$ voltage steps. Duration of each hyperpolarizing pulse was shortened as the potential values became more negative, as previously described (Zobeiri et al. 2018, 2019). Average current traces are shown. Inset, tail currents were measured at $-100 \mathrm{mV}$. c Average current-voltage relationship (I-V curve, left plot) and steady state of activation (SSA, right plot) curve for control (black, $n=6$ ) vs. "PACO"-like binge (red, $n=5$ ) treatments. SSA curves were fitted to the Boltzmann equation: $\mathrm{I} / \mathrm{I}_{\max }=1 /$ $\left(1+\exp .\left(\left(V-V_{50}\right) / k\right)\right.$; where $V$ is the membrane holding potential of the prepulse, $V_{50}$ is the membrane potential in which half of $\mathrm{I}_{\mathrm{H}}$ is activated, and $k$ is the slope or "slow factor." Right bar plots representing average $V_{50}$ and $k$, including dots correspondieng to individual data points. *Significantly different from control, $p<0.05$. Two-way RM ANOVA, testing voltages ( -100 to $-130 \mathrm{mV}, F_{(3,27)}$ : 171.46) and treatments $\left(F_{(1,27)}: 6.42\right)$. There was not a statistically significant interaction between applied voltage values and treatments. $\mathbf{d}$ Bar plots comparing the mean $\mathrm{I}_{\mathrm{H}}$ density at $-130 \mathrm{mV}$ for controls $(n=6)$, "PACO"-like administration $(n=5)$ and administration of either cocaine $(n=6)$ or caffeine $(n=6)$. *Significantly different from control, $p<0.05$, Student's $t$ test, $t_{9}=-$ 2.330. ${ }^{\circ}$ Significantly different from control and caffeine, $p<0.05$, ANOVA, $F_{3,19}=3.736$. e Blocking effect of an T-type specific blocker, TTA-A2 $(10 \mu \mathrm{M})$. T-type current $\left(\mathrm{I}_{\mathrm{T}}\right)$ was evoked by a despolaring pulse from a $\mathrm{V}_{\mathrm{H}}=-100 \mathrm{mV}$ to $-40 \mathrm{mV}$ (in an ACSF $+3 \mu \mathrm{M}$ TTX, $10 \mathrm{mM}$ TEA, $50 \mu \mathrm{M}$ DL-AP-5, $20 \mu \mathrm{M}$ CNQX, $50 \mu \mathrm{M}$ Bicuculline). Current traces showing time course of TTA-A2 bath application (1 trace/100 s), reaching its maximum blocking effect after $\sim 12$ min. $\mathbf{f} \mathrm{I}_{\mathrm{T}}$ activation protocol comparing VB neurons from control vs. "PACO"-like binge treated mice, using a protocol of holding potentials from $-100 \mathrm{mV}$ $(100 \mathrm{~ms})$ to $-40 \mathrm{mV}(50 \mathrm{~ms})$, at $5 \mathrm{mV}$ voltage steps. Average traces are shown. $\mathrm{g}$ Average current-voltage relationship (I-V curve) for control $(n=9)$ and "PACO"-like binge $(n=10)$ treatments. NS, no significantly difference between treatments ( $p>0.05$, two-way RM ANOVA). h Bar plots comparing mean $\mathrm{I}_{\mathrm{T}}$ density (including dots correspondieng to individual data points) at $-45 \mathrm{mV}$ for controls $(n=9)$, "PACO"-like binge $(n=10)$ and administration of either cocaine $(n=6)$ or caffeine $(n=6)$. *Significantly different from control and "PACO"-like binge, $p<$ 0.001. ANOVA. $F_{3,27}=9.574$.

currents. Ratiometric $\left[\mathrm{Ca}^{2+}\right]$ indicator Fura-2 $(0.5 \mu \mathrm{M})$ was added to the intracellular solution and VB neurons were allowed to passively reach a steady-state filling after gaining access to the cytoplasm for 5-10 min. Figure $4 \mathrm{~b}$ shows digital images of a single VB neuron after a "PACO"-like binge treatment, which represent the raw $380 \mathrm{~nm}$ fluorescence intensity and the pseudocolor representation of the fluorescence ratio $(340 \mathrm{~nm} / 380 \mathrm{~nm})$ at the resting (baseline) and during the inhibitory current step (LTS). $\left[\mathrm{Ca}^{2+}\right]_{\mathrm{i}}$ was determined from background-subtracted ratio values $(340 \mathrm{~nm} / 380 \mathrm{~nm})$ as previously described by (Usachev et al. 1993; Rankovic et al. 2010; Di Guilmi et al. 2014). Figure 4c shows averaged $\left[\mathrm{Ca}^{2+}\right]_{\mathrm{i}}$ values for the baseline period before stimulus presentation (typically $\sim 7 \mathrm{~s},\left[\mathrm{Ca}^{2+}\right]_{\text {basal }}$ ). In order to avoid calcium-induced calcium release mechanisms, internal calcium stores were depleted after exposing some neurons to bathapplied caffeine (20 mM; Usachev et al. 1993) for $10 \mathrm{~min}$ before applying the imaging protocol after reaching baseline $\left[\mathrm{Ca}^{2+}\right]$ levels of the recorded VB neuron (+caffeine, Fig. $4 \mathrm{c}$ ). The basal level of $\left[\mathrm{Ca}^{2+}\right]_{\mathrm{i}}$ was increased $\sim 3$ times after acute "PACO"-like binges (ANOVA, $p<0.05)$. This increase is still observed after depleting internal calcium stores $(\sim 2$ times; Mann-Whitney, $p<0.05)$, according to the observed increase of T-type "window currents" (Fig. 3f). No differences were observed after separately administrations of cocaine or caffeine. Figure $4 d$ depicts a typical response of a VB neuron during an inhibitory current step for control and "PACO" like binge treatments. The raw intensity values for the individual wavelengths (340 and $380 \mathrm{~nm}$ ) resulted in a maximal crossover (and, hence, ratio value) when intracellular calcium levels increased (see right panel in Fig. 4b). Crossover of the individual wavelength intensities was indeed dramatic when the inhibitory current step pulse was applied to a neuron from a "PACO"-like binge treatment. Figure 4e shows the time course of averaged $\left[\mathrm{Ca}^{2+}\right]_{\mathrm{i}}$ dynamics, whose basal level was increased after a "PACO"-like binge as seen in Fig. 4c. Indeed, the rise in $\left[\mathrm{Ca}^{2+}\right]_{i}$ was abrupt after the stimulus presentation to neurons acutely treated with "PACO"-like binges and subsequently returned to baseline (Fig. 4e). Figure $4 \mathrm{f} \mathrm{de-}$ picts the average of peak $\left[\mathrm{Ca}^{2+}\right]_{\mathrm{i}}$ values obtained during hyperpolarizing current steps $\left(\left[\mathrm{Ca}^{2+}\right]_{\text {LTS }}\right)$. No differences were observed after separately administrations of cocaine or caffeine. Regardless of bath-applied caffeine, $\left[\mathrm{Ca}^{2+}\right]_{\text {LTS }}$ was increased after acute "PACO"-like binges.

\section{Increase of basal $\left[\mathrm{Ca}^{2+}\right]_{\mathrm{i}}$ mediated by an acute "PACO"-like binge treatment modulates the biophysical properties of T-type voltage-gated calci- um channels}

Since an acute "PACO"-like binge administration increased the basal $\left[\mathrm{Ca}^{2+}\right]_{\mathrm{i}}\left(\right.$ Fig. $4 \mathrm{c}$ ) and prevented the increase of $\mathrm{I}_{\mathrm{T}}$ that was observed after separately administrations of cocaine or caffeine (Fig. 1f-h), we hypothesized that T-type $\mathrm{Ca}^{2+}$ channels might be partially blocked by a basal increase of $\left[\mathrm{Ca}^{2+}\right]_{i}$ after a acute "PACO"-like binge.

In order to evaluate our hypothesis, we studied the T-type $\mathrm{Ca}^{2+}$ current-voltage relationship (I-V curve) after intracellular dialyzing of the recorded neuron with 0.5 or $10 \mathrm{mM}$ EGTA (a calcium chelator included in the pipette solution) comparing control and acute "PACO"-like binge treatments (Fig. 5ac) (Marty and Neher 1985; Roberts 1993; Deisseroth et al. 1996). Under control conditions, no significant changes in I$\mathrm{V}$ curves were observed between 0.5 and $10 \mathrm{mM}$ EGTA (Fig. $5 \mathrm{a}, \mathrm{b})$ (two-way RM ANOVA, $p>0.05$ ). However, after an acute "PACO"-like binge, increasing the EGTA concentration 


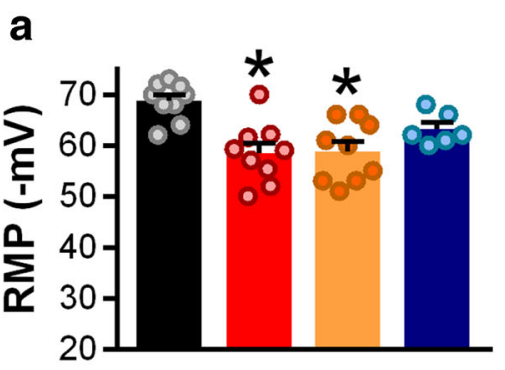

d

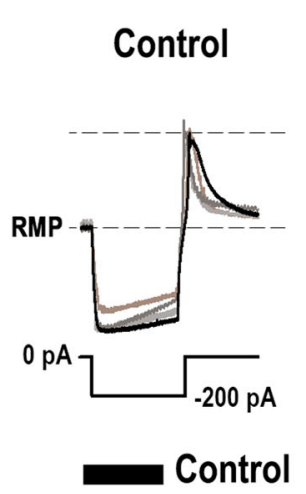

b

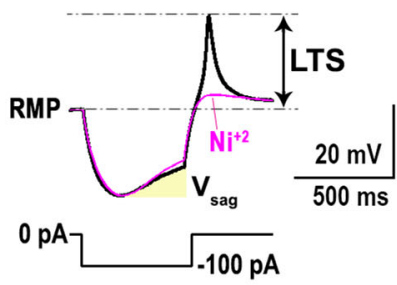

c

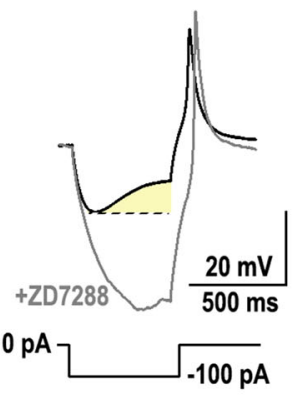

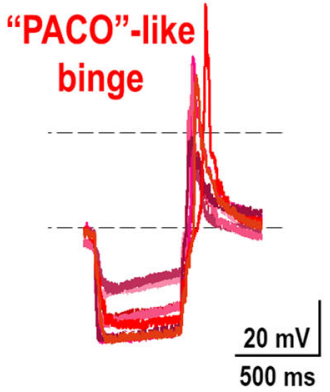

"PACO"-like binge (Cocaine+Caffeine) e

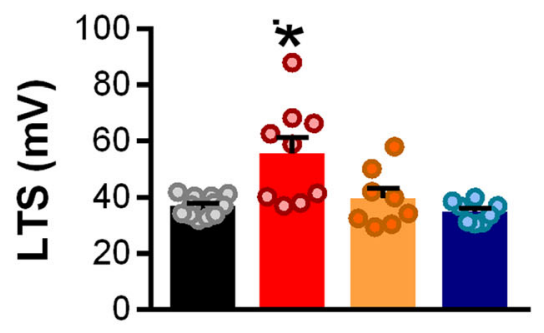

Fig. 2 An acute "PACO"-like binge administration increased lowthreshold spike (LTS) amplitude in VB neurons. a Resting membrane potential (RMP) recorded in VB neurons $24 \mathrm{~h}$ after all binge groups (control, $n=9$; "PACO"-like, $n=9$; cocaine, $n=9$; or caffeine, $n=6$ ). $*$ Significantly different from control, $p<0.05$, ANOVA. $F_{2,24}=10.98$. b Representative trace of a VB neuron recorded in current-clamp (in an ACSF $+3 \mu \mathrm{M}$ TTX, $10 \mathrm{mM}$ TEA, $50 \mu \mathrm{M}$ AP-5, $20 \mu \mathrm{M}$ CNQX, $50 \mu \mathrm{M}$ Bicuculline). Low-threshold spikes (LTS) were triggered by a hyperpolarizing square pulse $(-100 \mathrm{pA})$. LTS were blocked by nickel $\left(\mathrm{Ni}^{2+}, 100 \mu \mathrm{M}\right)$. $\mathrm{c}$ Blocking effect of the specific blocker of HCN channels, ZD7288 (30 $\mu \mathrm{M})$, in current-clamp recording mode. d Overlapping LTS responses for controls and "PACO"-like binge treatments. LTS were triggered by a hyperpolarizing square pulse $(-200 \mathrm{pA})$. e Changes in LTS amplitude for controls $(n=12)$, "PACO"-like $(n=9)$, cocaine $(n=$ $8)$, and caffeine $(n=8)$ treatments. *Significantly different from other treatments, $p<0.05$, Kruskal-Wallis ANOVA on Ranks, $\mathrm{H}_{3}=11.82$ from 0.5 to $10 \mathrm{mM}$ shifted the peak of the $\mathrm{I}-\mathrm{V}$ curve by $12 \mathrm{mV}$ in the hyperpolarizing direction $(-46.7 \pm 1.0 \mathrm{mV}$ vs. $-58.3 \pm 1.0 \mathrm{mV}$ ) and increased its current density by $\sim 40 \%$ $(-4.2 \pm 0.8 \mathrm{pA} / \mathrm{pF}$ vs. $-6.0 \pm 0.6 \mathrm{pA} / \mathrm{pF}$ ) (two-way $\mathrm{RM}$ ANOVA, $p<0.01$, Fig. 5a and c). These results support the idea that the basal increase of $\left[\mathrm{Ca}^{2+}\right]_{i}$ partially blocked and shifted the voltage dependence of T-type $\mathrm{Ca}^{2+}$ channels. These results also suggested that the separately effect of cocaine and/or caffeine on T-type currents (Fig. 1h) was uncovered when $10 \mathrm{mM}$ EGTA was included in the recording pipette solution (Fig. 5c).

Furthermore, biophysical properties of activation and inactivation were studied after dialyzing neurons with $10 \mathrm{mM}$ EGTA. We have compared these experiments with those presented in Fig. 3 (b and d), which were performed with a 0.5 mM-EGTA in the pipette solution (Fig. $5 \mathrm{~d}-\mathrm{g}$ ). Under control condition, both activation and steady-state inactivation curves were not affected by increasing the EGTA concentration in the pipette solution from 0.5 to $10 \mathrm{mM}$ (Fig. 5d). Figure 3 (b and d) showed that both activation and steady-state inactivation curves were shifted towards depolarizing potential after an acute "PACO"-like binge compared to control $(0.5 \mathrm{mM}$ EGTA was included in the pipette solution). Importantly, increasing the EGTA concentration in the pipette solution to $10 \mathrm{mM}$ prevented the depolarizing shift of both activation and steady-state inactivation curves (Fig. 5e) and their average midpoint potentials $\left(\mathrm{V}_{50}\right)$ resemble those determined in control conditions (Fig. 5f, g). Similar behavior was observed for the activation slope factor $k$ (Fig. 5f, g). Table 2 summarizes $\mathrm{V}_{50}$ and slope factor $k$ average values in dialyzed neurons with either 0.5 or $10 \mathrm{mM}$ EGTA for both control and "PACO"-like binge treatments. Our results involved $\left[\mathrm{Ca}^{2+}\right]_{i}$-dependent mechanisms that modulate the biophysical properties of T-type $\mathrm{Ca}^{2+}$ channels, which critically link these calcium channels to their physiological functions.

\section{Chronic "PACO"-like binge administration alters H current mediated by HCN channels}

In contrast to acute binges, chronic "PACO"-like binges reduced $\mathrm{I}_{\mathrm{H}}$ density and shifted the membrane potential in which half $\mathrm{I}_{\mathrm{H}}$ was activated $\left(\mathrm{V}_{50}\right)$ towards hyperpolarizing values (two-way RM ANOVA, $p<0.001$, Fig. 6a-c). Consistently, 
we quantified using RT-qPCR that levels of HCN2 mRNA in the VB nucleus decreased by $\sim 55 \%(n=6$, Student's $t$ test, $\mathrm{t}_{10}=3.42, p<0.01$; data not shown). The acute effect of cocaine on $\mathrm{I}_{\mathrm{H}}$ density was no longer maintained when the administration became chronic (Fig. 6d). On the other hand, the chronic "PACO"-like binges did not inhibit but enhanced voltage-gated T-type currents density (ANOVA, $p<0.05$; Fig. 6e and f). Furthermore, no differences in $\mathrm{I}_{\mathrm{T}}$ density were observed when comparing whith the chronic cocaine administration (Fig. 6f). Interestingly, acute effects of "PACO"-like binges in basal $\left[\mathrm{Ca}^{2+}\right]_{\mathrm{i}}$ levels were no longer maintained after chronic binges (Fig. 6g). These results support our findings about a partial blockade of the T-type current density by an intracellular $\left[\mathrm{Ca}^{2+}\right]$ increase 24-h after an acute "PACO"-like binge, which returns to normal levels when the binge administration becomes chronic, uncovering solely cocaine effects on T-type currents (Fig. 6e and f).

Since we found no differences between LTS-associated $\mathrm{Ca}^{2+}$ transients after a chronic "PACO"-like binge respect to control, we assumed no apparent differences in biophysical properties of the T-type channel (Fig. 6h). In addition, the profound decrease of $\mathrm{I}_{\mathrm{H}}$ density and the hyperpolarizing shift of its activating curve after a chronic "PACO"-like binge (Fig. $6 \mathrm{a}-\mathrm{c})$ would generate a weak depolarizing force hindering the opening of the T-type $\mathrm{Ca}^{2+}$ channels and the generation of LTS-associated $\mathrm{Ca}^{2+}$ transients.

\section{Excitability of VB neurons 24-h after acute or chronic "PACO"-like binge administrations}

$\mathrm{H}$-currents tend to stabilize the resting membrane potential. The net effect of $\mathrm{HCN}$ channel activation is a decrease in the input resistance of the membrane (Magee 1998; Kase and Imoto 2012). Figure 7a shows a reduction of the input resistance in VB neurons 24-h after an acute "PACO"-like binge administration (Student's $t$ test, $p<0.05$ ), according to the observed increase of $\mathrm{I}_{\mathrm{H}}$ density (Fig. $1 \mathrm{~b}$ and c). Conversely, the input resistance increased 24-h after a chronic administration (Student's $t$ test, $p<0.05$ ), in line with the observed decrease of $\mathrm{I}_{\mathrm{H}}$ density and the hyperpolarizing shift of its activation (Fig. 6a-c). Furthermore, we studied the characteristic volage sag related to the level of $\mathrm{I}_{\mathrm{H}}$ activation in response to a hyperpolarizing current step $(-500 \mathrm{pA}$ for $500 \mathrm{~ms})$. As expected, the voltage sag ratio values were increased in VB neurons that underwent an acute "PACO"-like binge treatment (red trace). A significantly reduction in voltage sag ratios was observed 24-h after a chronic treatment (maroon trace, Fig. 7b; Student's $t$ test, $p<0.05$ ).

$\mathrm{I}_{\mathrm{H}}$-mediated alterations in membrane resistance will determine how the neurons respond to incoming stimulation (ie. level of voltage change) (Magee 1998; Kase and Imoto 2012). Therefore, membrane excitability was quantified by assessing the threshold and the number of APs with a current ramp stimulus (ramp rate of $0.67 \mathrm{pA} / \mathrm{ms}$ ) applied after hyperpolarizing the membrane ( $-200 \mathrm{pA}$ for $50 \mathrm{~ms}$ ) to activate $\mathrm{H}$ and Ttype currents. Action potentials triggered by a LTS were called low-threshold action potentials (LT AP) and those triguered later were called high-treshold action potentials (HT AP) (Fig. 7c). Membrane excitability decreased 24-h after an acute "PACO"-like binge (compare left and middle trace and see the $\mathrm{V}_{\text {sag }}$ in Fig. 7c). The threshold of both LT $\mathrm{AP}$ and HT AP was despolarized by $\sim 3.8$ and $5.5 \mathrm{mV}$, respectively (Student's $t$ test, $p<0.05$; Fig. 7d). In addition, the action potential number of HT APs was decreased by $\sim 60 \%$ (Student's $t$ test, $p<0.05$; Fig. 7e). Conversely, membrane excitability increased 24 -h after a chronic "PACO"-like binge. The threshold of LT AP was hyperpolarized by $\sim 3.3 \mathrm{mV}$ (Student's $t$ test, $p<0.05$ ) and no change was observed in the threshold of HT AP (Fig. 7d). However, the action potential number of both LT AP and HT AP was increased by 56 and $48 \%$, respectively (Student's $t$ test, $p<0.05$; Fig. 7e).

Overall, $24 \mathrm{~h}$ after an acute "PACO"-like binge administration, the enhancement of $\mathrm{I}_{\mathrm{H}}$ density decreases the input resistance, diminishing the intrinsic membrane excitability. Conversely, the reduction of $\mathrm{I}_{\mathrm{H}}$ density after a chronic administration increases the input resistance, allowing membrane potentials to move significantly closer to threshold, enhancing the intrinsic membrane excitability. The threshold of both LT AP and HT AP was depolarized after an acute "PACO"-binge admiministration, according to the depolarized RMP (Fig. 2a), likely resulting from the increase of not only $\mathrm{I}_{\mathrm{H}}$ but also T-type "window current" (Fig. 1b-c, 3f-g). When the administration became chronic, the threshold of LT AP was hyperpolarized as it was reported by Urbano et al. (2009) for VB neurons after cocaine binge administration.

\section{Can alterations at ventrobasal neurons by a chronic "PACO"-like administration affect sleep/awake phases during EEG/EMG recordings?}

Our results showed that an acute "PACO"-like binge administration produced notorious alterations in the physiology of VB neurons that increased LTS-associated $\mathrm{Ca}^{2+}$ transients and decreased the membrane excitability. We observed homeostatic changes when the administration became chronic; such as a downregulation of basal $\left[\mathrm{Ca}^{2+}\right]_{\mathrm{i}}$ to normal levels and a drastic reduction of $\mathrm{I}_{\mathrm{H}}$, which not only restablished the LTSassociated $\mathrm{Ca}^{2+}$ transients as observed in controls but also increased the membrane excitability to values even higher than control. In order to study the physiological impact of these chronic-mediated alterations on the sleep-wake transitions, we performed electroencephalography in mice 24 -h after a chronic "PACO"-like binge.

We recorded EEG/EMG in mice $24 \mathrm{~h}$ after being systemically treated with chronic administration of cocaine+caffeine $(n=5$ mice $)$ and with the administration of vehicle, saline $(n=$ 

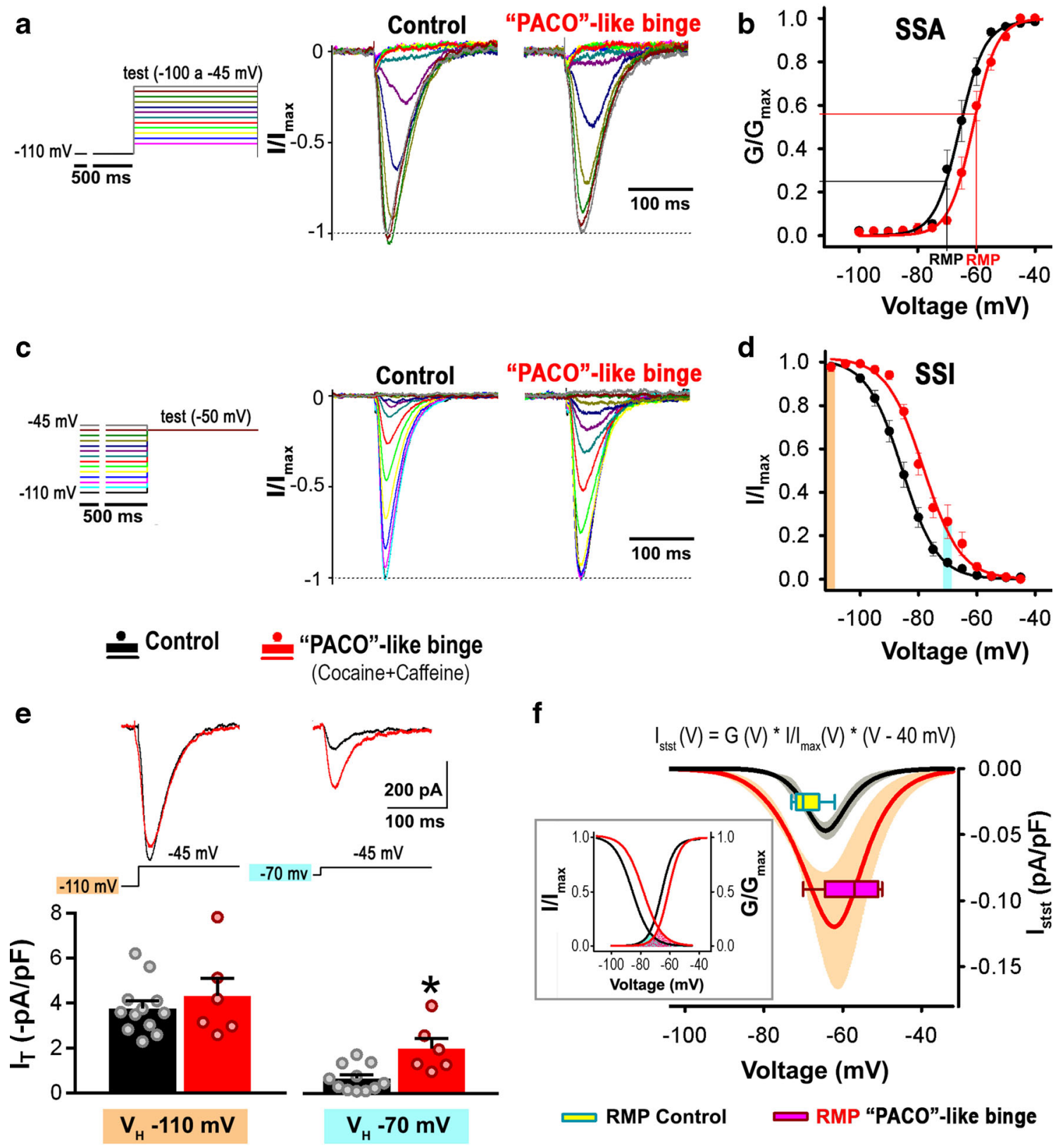

f

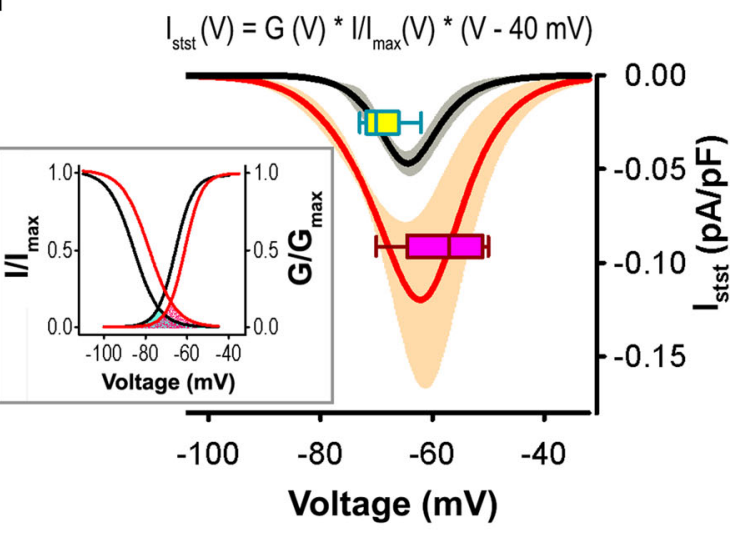

R RMP Control RMP "PACO"-like binge

g
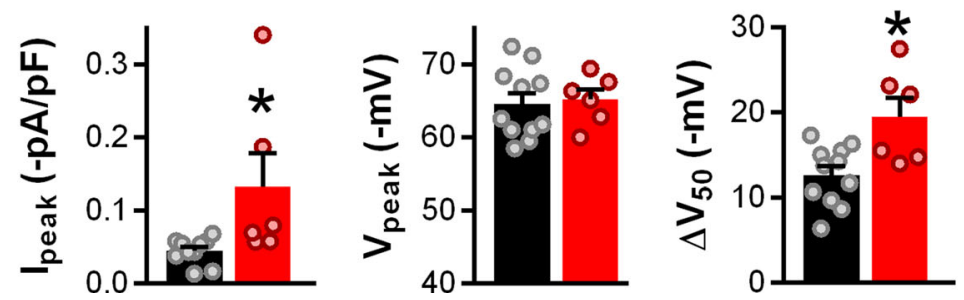

4 mice). We have programmed the last systemic drug administration $24 \mathrm{~h}$ before EEG/EMG recordings. Recordings started $2 \mathrm{~h}$ before light cycle change (that is, $18 \mathrm{~h} 2 \mathrm{~h}$ of turning off the light at 20:00 h) and lasted until 8 a.m. the following day. Percentages of time in the awake, NREM, and REM stages were plotted for every hour of recording
(Fig. 8) comparing animals chronically treated with the "PACO"-like binge versus vehicle. Greater awake percentage of time was observed after chronic "PACO"-like binges treatment compared to saline (Fig. 8a, b). One-way RM ANOVA comparison showed that treatment significantly affected awake times $F_{(1,7)}=94.6 ; p<0.001$ (Fig. 8a). Mean total 
Fig. 3 Effects of acute "PACO"-like binge on T-type calcium current properties in VB neurons. a Steady-state activation (SSA) protocol of low-threshold T-type calcium currents. Holding potential $\left(\mathrm{V}_{\mathrm{H}}\right)$ was maintained at $-110 \mathrm{mV}$ for $500 \mathrm{~ms}$, then it was changed using square pulses from -100 to $-45 \mathrm{mV}$ in $5 \mathrm{mV}$ steps. Average current traces for control $(n=10)$ and "PACO"-like binge $(n=6)$ groups are shown. b Average steady-state activation (SSA) values (and solid lines fitted to a Boltzmann equation) for control (black dots) and "PACO"-like binge (red dots) groups expressed as individual/maximum conductance ratio $\left(\mathrm{G} / \mathrm{G}_{\max }\right)$ as a function of holding voltage. The value of the resting membrane potentials (RMP) for both treatments is indicated on the abscissa axis. c T-type currents steady-state inactivation (SSI) protocol using a holding potential maintained at $-110 \mathrm{mV}$ for $500 \mathrm{~ms}$, then it was changed using square pulses from -100 to $-45 \mathrm{mV}$ at $5 \mathrm{mV}$ steps, followed by a holding square test pulse of $-50 \mathrm{mV}$. Average current traces for control $(n=10)$ and "PACO"-like binge $(n=6)$ groups are shown. $\mathbf{d}$ Average steady-state inactivation (SSI) values (and solid lines fitted to a Boltzmann equation) for control (black dots) and "PACO"-like binge (red dots) groups expressed as individual/maximum current $\left(\mathrm{I} / \mathrm{I}_{\max }\right)$ as a function of holding voltage. Orange bar on the left showed 100\% of Ttype channels were de-inactivated. Light blue bar illustrates holding potential of $-70 \mathrm{mV}$. Note how "PACO"-like binge values were 3 -fold bigger than control. e Above: Representative T-type current traces for control (black line) or "PACO"-like binge (red line) treatment groups. Below: average $I_{T}$ current density values were elicited from a $V_{H}$ of either $-110 \mathrm{mV}$ (left) or $-70 \mathrm{mV}$ (right); same holding values are represented in 4D as orange and light blue bars, respectively. *Significantly different from control (Student's $t$ test; $t_{15}=3.34, p=0.002$; for control, $n=10$ and for "PACO" like binge, $n=6$. f Left inset: overlapping steady-state activation and inactivation curves of control and cocaine + caffeine obtained as Boltzmann fitting from (b) and (d). Note light blue and pink "shaded" colored areas representing the "window current" for control and "PACO"-like binge treatments, respectively. Right curve: $\mathrm{I}_{\mathrm{T}}$ currents at the steady-state level [See the above equation used to calculate the theoretical "Window current"; $\mathrm{I}_{\mathrm{T} \text { (stst })}=\mathrm{G}\left(\mathrm{V}_{\mathrm{H}}\right) * \mathrm{I}_{\mathrm{T}} / \mathrm{I}_{\mathrm{T}, \mathrm{ma}} \mathrm{x}\left(\mathrm{V}_{\mathrm{H}}\right) *\left(\mathrm{~V}_{\mathrm{H}}\right.$ at $40 \mathrm{mV}$ )], without normalizing $\mathrm{G}$, for each treatment. The black line represents the average currents in control, while the gray area around it representing its standard error. The red line and orange area represent values obtained after a "PACO"-like binge treatment. Boxplots indicated average resting membrane potential (RMP) for each treatment. g Comparison of key average parameters corresponding to the curves represented in (f). *Significantly different from control. Student's $t$ test; $t_{15}=$ 2.4, $p=0.01$; for control $n=11$, for "PACO"-like binge $n=6$ )

awake time were also significantly different (Fig. 8b; Student's $t$ test, $\mathrm{df}=13 ; t=4.5 ; p<0.001)$. On the other hand, NREM sleep percentage of time was reduced after chronic "PACO"-like binge treatment (Fig. 8c; RM ANOVA $\left.F_{(1,7)}=10.5 ; p<0.05\right)$. Mean total NREM reduction was also significantly different (Fig. 8d; Student's $t$ test, $\mathrm{df}=13 ; t=$ 2.6; $p<0.05)$. There are no changes in REM sleep percentage of time (Fig. 8e; RM ANOVA $F_{(1,7)}=0.8 ; p>0.05$ ).

\section{Discussion}

This study provides evidence that acute and chronic administrations of a cocaine and caffeine mixture, resembling a sample of cocaine paste base or "PACO", produce notorious alterations in intracellular calcium dynamics and dysregulate $\mathrm{HCN}$-mediated and T-type conductances in thalamic ventrobasal (VB) neurons of mice. All these changes ultimately modulated the membrane excitability, altering sleep-wake transitions.

Thalamic electrophysiology recordings have previously shown that brain rhythms (using electroencephalogram recordings) had a counterpart in the rhythmic oscillations and action potentials discharge that occur at single-cell level (Steriade and Amzica 1996). Altered plasma membrane expression of several voltage-gated ion channels of Ventrobasal (VB) neurons (specific thalamocortical neurons) has been proposed as the etiology of stimulants-mediated effects. Our group previously work showed how cocaine systemic administration mediated both hyperlocomotion and the increase of T-type calcium channel expression at thalamocortical VB neurons (Urbano et al. 2009; Bisagno et al. 2010; Goitia et al. 2013, 2016). Moreover, the increase of T-type and HCN currents, plus the enhancement of synaptic GABAergic activity induced by cocaine administration in mice, was suggested to "lock" the whole thalamocortical system into low frequencies in the EEG (Urbano et al. 2009). Thus, characterizing how effects of "PACO"-like administration affected VB neurons intrinsic properties allowed our group to dissect important underlining mechanisms of the described alterations of sleep-wake transitions during EEG recordings.

\section{Alterations in $\left[\mathrm{Ca}^{2+}\right]_{i}$ mediated by acute "PACO"-like binge treatments might be the key factor underlying changes on T-type and HCN channels at ventrobasal thalamic nucleus}

The current density mediated by $\mathrm{HCN}$ channels $\left(\mathrm{I}_{\mathrm{H}}\right)$ increased 24-h after an acute "PACO"-like binge administration with a concomitant depolarization of the resting membrane potential (RMP), similarly to an acute binge of cocaine. In line with our experiments, $\mathrm{I}_{\mathrm{H}}$ upregulation has been previously described in VB neurons 1-h after the administration of a cocaine binge (Urbano et al. 2009; Bisagno et al. 2010). Therefore, $I_{H}$ alteration observed 24-h after an acute "PACO"-like binge could be attributed to cocaine effects.

T-type $\mathrm{Ca}^{2+}$ current $\left(\mathrm{I}_{\mathrm{T}}\right)$ density decreased 24-h after an acute "PACO"-like binge administration. Conversely, separately administration of cocaine or caffeine increased $\mathrm{I}_{\mathrm{T}}$ density similar to previously reported for an acute binge of cocaine (Urbano et al. 2009). Our experiments showed an increase of basal $\left[\mathrm{Ca}^{2+}\right]_{\mathrm{i}}$ in VB neurons after an acute "PACO"like binge treatment. Interestingly, we revealed a calciumdependent inhibition of $\mathrm{I}_{\mathrm{T}}$ after dializing the neuron with $10 \mathrm{mM}$ EGTA, unmasking cocaine and/or caffeine effects on $\mathrm{I}_{\mathrm{T}}$. In line with our experiments, it has been described that the presence of ionomycin (an ionophore that allows calcium channels to enter the cell) partially blocked T-type currents in primary cultures of dorsal root ganglia neurons (Cazade et al. 
a

Image acquisition $\left(\lambda_{E X}: 340,380 \mathrm{~nm}\right)$

$\left[\mathrm{Ca}^{2+}\right]_{\text {basal }} \quad\left[\mathrm{Ca}^{2+}\right]_{\text {LTS }}$

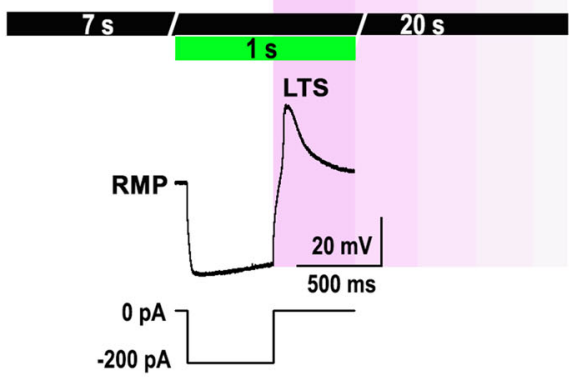

b

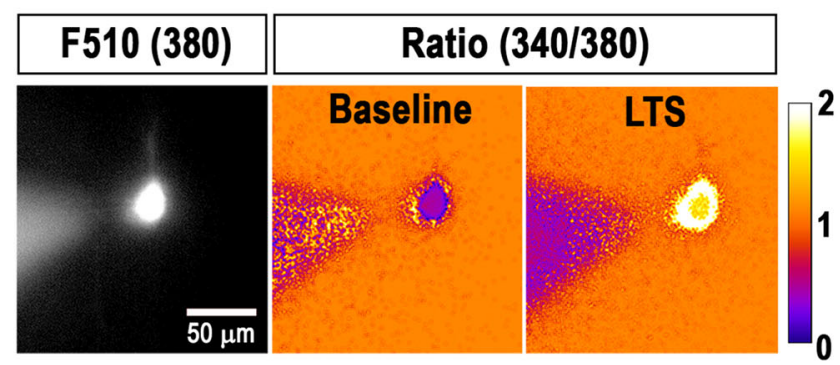

C
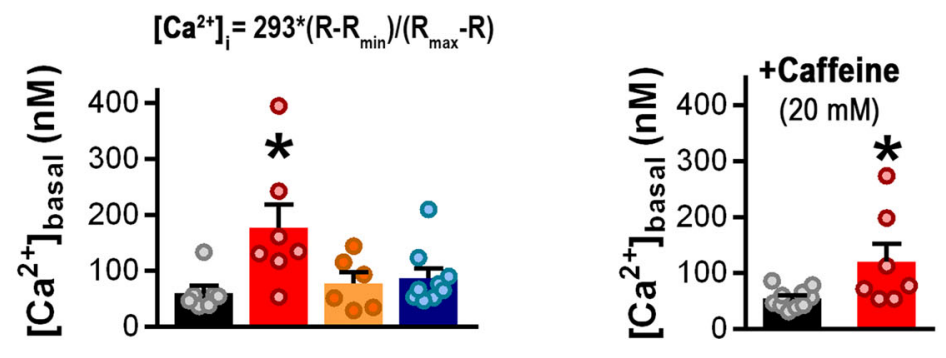

d
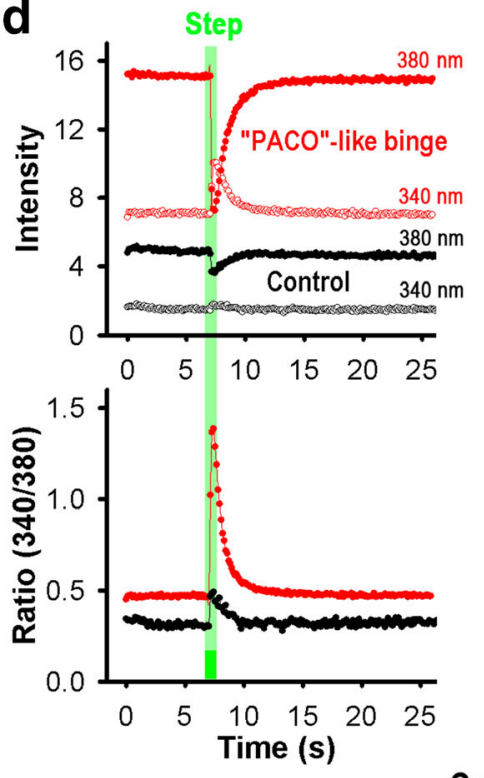

e

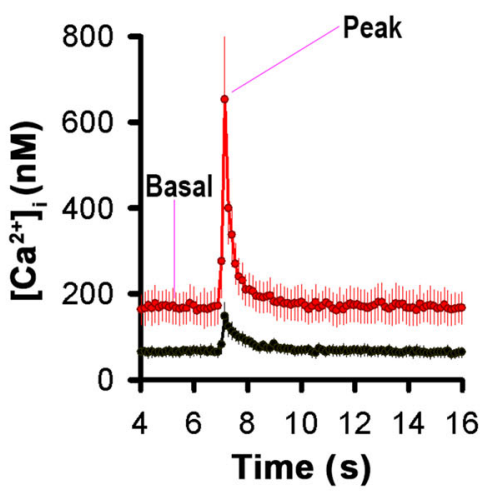

f
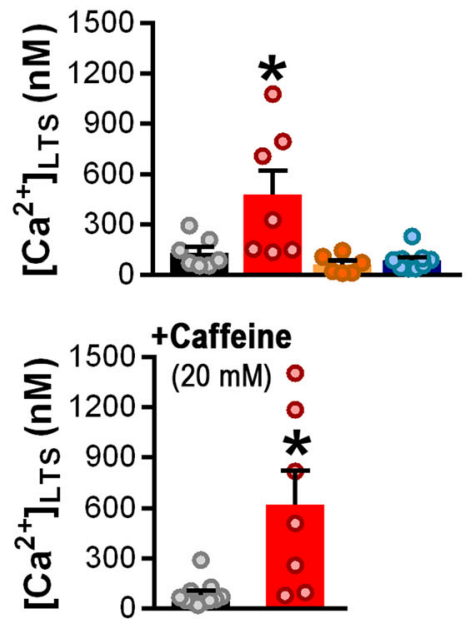

Control
"PACO"-like binge

(Cocaine+Caffeine)
Cocaine

Caffeine
2017). Furthermore, other authors have shown that calmodulin and the T-type, $\mathrm{Ca}_{\mathrm{V}} 3.1$ channels are constitutively associated, and $\left[\mathrm{Ca}^{2+}\right]$ influx through the channel pore was sufficient to activate $\alpha-\mathrm{Ca}^{2+}$-calmodulin kinase II (Asmara et al. 2017). A direct regulation of T-type $\mathrm{Ca}_{\mathrm{V}} 3.2$ channels by $\mathrm{Ca}^{2+}$-calmodulin kinase II has also been described (Welsby et al. 2003).

We found that T-type $\mathrm{Ca}^{2+}$ channels in VB neurons were dynamically regulated by changes in $\left[\mathrm{Ca}^{2+}\right]_{\mathrm{i}}$. Indeed, 24-h after an acute "PACO"-like binge treatment, we observed a rightward shift of both the steady-state inactivation and activation curves of T-type $\mathrm{Ca}^{2+}$ channels; which was prevented by the addition of $10 \mathrm{mM}$ EGTA to the pipette solution. These results further described that steady-state properties of T-type channels are finely modulated by basal $\left[\mathrm{Ca}^{2+}\right]_{i}$ enhancements mediated by acute "PACO"-like binge administrations. Indeed, our results suggested that after an acute "PACO"-like binge, a large fraction of T-type $\mathrm{Ca}^{2+}$ channels would be deinactivated in response to an inhibitory input. In addition, the depolarizing effect of a "PACO"-like binge on the RMP 
4 Fig. 4 Acute "PACO"-like binge increased intracellular basal calcium and LTS-associated $\mathrm{Ca}^{2+}$ transients in VB neurons. a Above, illustrating drawing of the acquisition protocol used to determine basal and LTSassociated $\left[\mathrm{Ca}^{2+}\right]_{\mathrm{i}}$ transients $\left(\left[\mathrm{Ca}^{2+}\right]_{\text {basal }},\left[\mathrm{Ca}^{2+}\right]_{\text {LTS }}\right)$. We used a hyperpolarizing current step ( $-200 \mathrm{pA}$ for $500 \mathrm{~ms}$ ) to elicit a LTS spike (in an $\mathrm{ACSF}+3 \mu \mathrm{M}$ TTX, $10 \mathrm{mM}$ TEA, $50 \mu \mathrm{M}$ AP-5, $20 \mu \mathrm{M}$ CNQX, $50 \mu \mathrm{M}$ Bicuculline). Below, representative LTS. Images were acquired $7 \mathrm{~s}$ before (baseline) and $20 \mathrm{~s}$ after the stimulation protocol (1 s duration). b Representative raw fluorescence emission image $(510 \mathrm{~nm})$ from a Fura2-filled VB neuron excited at 380-nm wavelength (left) 24-h after a "PACO"-like binge treatment. A pseudo color scheme has been applied after calculating the fluorescence ratio $\mathrm{F}($ Ratio $)=\mathrm{F} 340 / \mathrm{F} 380$ at the resting (baseline, middle) and during the inhibitory current step (LTS, right). White scale bar represents size of recorded area. Scale bar on the right indicates with white as the highest and black as the lowest fluorescence ratio. c Left: basal intracellular calcium concentration $\left(\left[\mathrm{Ca}^{2+}\right]_{\text {basal }}\right)$ was calculated averaging $\left[\mathrm{Ca}^{2+}\right]_{\mathrm{i}}$ values for the baseline period (typically $7 \mathrm{~s}$ ), using the formula: $293 *\left(R-R_{\min }\right) /\left(R_{\max } R\right) . R_{\min }$ was the minimum ratio obtained in the absence of calcium and $R_{\max }$ is the highest ratio value obtained when Fura-2 is saturated and was calculated as previously described (Usachev et al. 1993; Rankovic et al. 2010; Di Guilmi et al. 2014). Mean \pm SEM values are presented for control $(n=7)$, "PACO"-like $(n=$ $7)$, cocaine $(n=6)$, and caffeine $(n=10)$ treatments. *Significantly different from control, $p<0.05$. Kruskal-Wallis ANOVA on Ranks, $\mathrm{H}_{3}=8.65$. Right: Internal calcium stores were depleted applying caffeine $(20 \mathrm{mM}$; Usachev et al. 1993) to the bath for $10 \mathrm{~min}$ before images acquisition (+ caffeine). Mean \pm SEM values are presented for control $(n=10)$, "PACO"-like $(n=7)$. *Significantly different from control, $p<0.05$. Mann-Whitney, $U_{\text {Statistic }}=14.0$. d Top: raw intensity values for 340 and 380-nm excitation wavelengths for a VB neuron after control and "PACO"-like binge treatments. See the baseline and the crossover of the individual wavelength intensities before and after the stimulus application (marked in green). Bottom: ratio values of these individual wavelength intensities that were calculated offline (Ratio[340/380]). e Time course of averaged $\left[\mathrm{Ca}^{2+}\right]_{i}$ dynamics for control and "PACO"-like binge treatments (each one $n=7$ ) before, during, and after the hyperpolarizing inhibitory current step stimulus. f Top: LTS-associated $\mathrm{Ca}^{2+}$ transients $\left(\left[\mathrm{Ca}^{2+}\right]_{\mathrm{LTS}}\right)$ calculated as peak $\left[\mathrm{Ca}^{2+}\right]_{\mathrm{i}}$ obtained during the inhibitory current step. Mean \pm SEM values are presented for control (black; $n=7$ ), "PACO"like (red; $n=7$ ), cocaine (yellow, $n=6$ ) and caffeine (blue, $n=9$ ) treatments. *Significantly different from other treatments, $p<0.05$. KruskalWallis ANOVA on Ranks, $\mathrm{H}_{3}=13.19$. Bottom: $\left[\mathrm{Ca}^{2+}\right]_{\text {LTS }}$ after applying caffeine $(20 \mathrm{mM})$ to the bath for $10 \mathrm{~min}$ before images acquisition (+ caffeine). Mean \pm SEM values are presented for control (black, $\mathrm{n}=11$ ) or "PACO"-like (red, $n=7$ ). *Significantly different from control, $p<0.05$. Mann-Whitney, $U_{\text {Statistic }}=7.0$

would increase the activable fraction of deinactivated T-type $\mathrm{Ca}^{2+}$ channels when the membrane potential suddenly reached its resting value at the end of this inhibitory input, and in combination with $\mathrm{I}_{\mathrm{H}}$ current-deactivation would also favor the generation of large low-threshold spike (LTS)-associated $\mathrm{Ca}^{2+}$ transients. Our results are also consistent with previous reports, describing how intracellular $\mathrm{Ca}^{2+}$ released from internal stores finally shaped LTS in reticular thalamic neurons (Coulon et al. 2009). On the other hand, the observed increase of $\mathrm{I}_{\mathrm{H}}$ density after an acute "PACO"-like binge administration would stabilize the resting potential of VB neurons (Meuth et al. 2006; Brennan et al. 2016; Zobeiri et al. 2019), enhancing even more the amplitude of LTS, given the functional and physical association between HCN and T-type channels (Fan et al. 2017).

Solely, the acute administration of cocaine combined with caffeine ("PACO"-like binge) produced a large increase of basal $\left[\mathrm{Ca}^{2+}\right]_{\mathrm{i}}$ that persisted after 24-h; separately administration of these stimulants did not produce any effect on $\left[\mathrm{Ca}^{2+}\right]_{\mathrm{i}}$. Caffeine concentration $(5 \mathrm{mg} / \mathrm{kg})$ used in this work has been associated with caffeine brain levels in the tens of micromolar range (Heppert and Davies 1999; Goitia et al. 2016). Such caffeine concentration levels have been ascribed to adenosine receptor blockage (Fredholm 1995; Fredholm et al. 1999), rather than acting through the inhibition of phosphodiesterase (Aoyama et al. 2011), or the opening of ryanodine and $\mathrm{IP}_{3}$ receptors (Garaschuk et al. 1997; Rankovic et al. 2010). Caffeine is a known activator of ryanodine receptors located in the endoplasmic reticulum (Rankovic et al. 2010; Usachev et al. 1993). We expect that each systemic administration of caffeine would produce a transient increment of intracellular $\left[\mathrm{Ca}^{2+}\right]$ mediated in part by ryanodine receptors opening on thalamocortical/corticothalamic networks. Repetitive caffeine administration would sensitize ryanodine receptors, allowing them to be more sensitive to smaller cytosolic increments in $\left[\mathrm{Ca}^{2+}\right]$ (Verkhratsky and Shmigol 1996). Indeed, bath application of caffeine $(+20 \mathrm{mM})$ elicited three fold $\left[\mathrm{Ca}^{2+}\right]$ levels after acute "PACO"-like binges. A new group of experiments are still needed in order to functionally link $\left[\mathrm{Ca}^{2+}\right]_{\mathrm{i}}$ transients after caffeine systemic administrations and the described dysregulation of HCN and T-type channels that we observed 24-h after acute/chronic "PACO"-like administration.

On the other hand, it has been reported that an acute cocaine dose $(1 \mathrm{mg} / \mathrm{kg})$ induced in vivo a large increase of $\left[\mathrm{Ca}^{2+}\right]_{\mathrm{i}}$ in the cortex of the rat brain (Du et al. 2006). Similarly, VB neurons exhibited high levels of $\left[\mathrm{Ca}^{2+}\right]_{\mathrm{i}} 1-\mathrm{h}$ after an acute cocaine administration (3 injections, $15 \mathrm{mg} / \mathrm{kg}$ each, 1 h apart) (Rozas et al. 2017). However, our experiments were performed 24-h after the acute cocaine administration. We do not exclude the possibility that caffeine enhances the effect of cocaine leading to a dysregulation of $\left[\mathrm{Ca}^{2+}\right]_{\mathrm{i}}$ homeostasis. Indeed, our results showed that 24-h after an acute "PACO"-like binge administration, the calcium-dependent modulation of T-type biophysical properties resulted in a great increase of $\mathrm{I}_{\mathrm{T}}$-mediated "window currents," suggesting that a large subset of T-type channels would be permanently opened at resting membrane potential, leading to a stationary $\mathrm{Ca}^{2+}$ influx and a persistent enhancement of $\left[\mathrm{Ca}^{2+}\right]_{\mathrm{i}}$. Moreover, it is known that calcium entry through T-type channels stimulates the release of calcium from intracellular compartments (Richter 2005).

However, when "PACO"-like binge administration became chronic, basal $\left[\mathrm{Ca}^{2+}\right]_{\mathrm{i}}$ returned to normal levels, whereby $\mathrm{I}_{\mathrm{T}}$ density was no longer inhibited, reaching enhanced values as observed after a chronic administration of cocaine. Likewise, Goitia et al. (2013) reported that thalamic VB 
a

Control

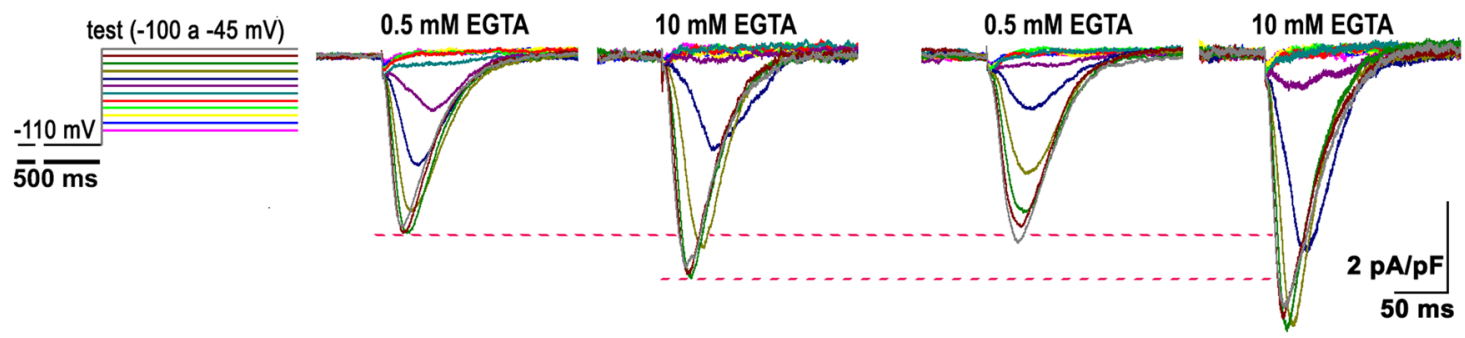

b

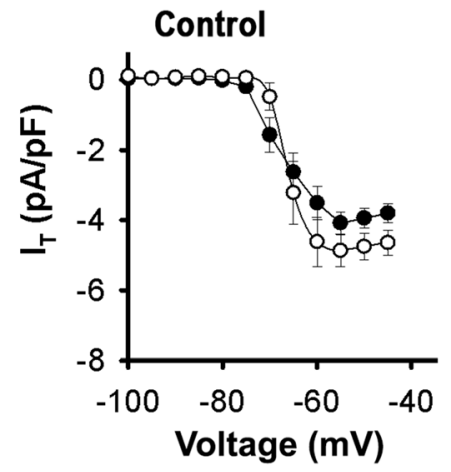

d

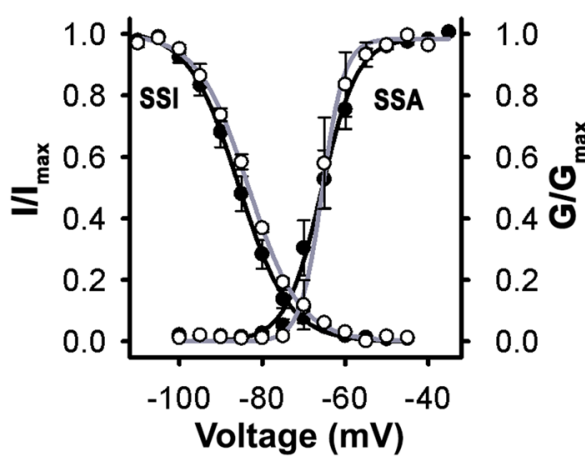

$\mathbf{f}$

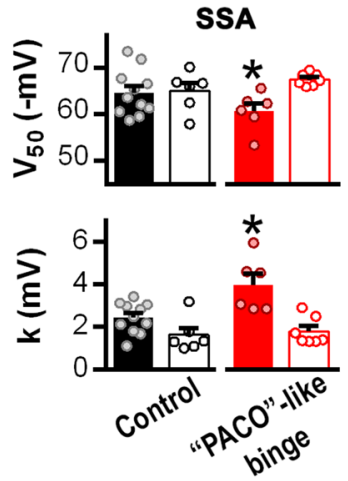

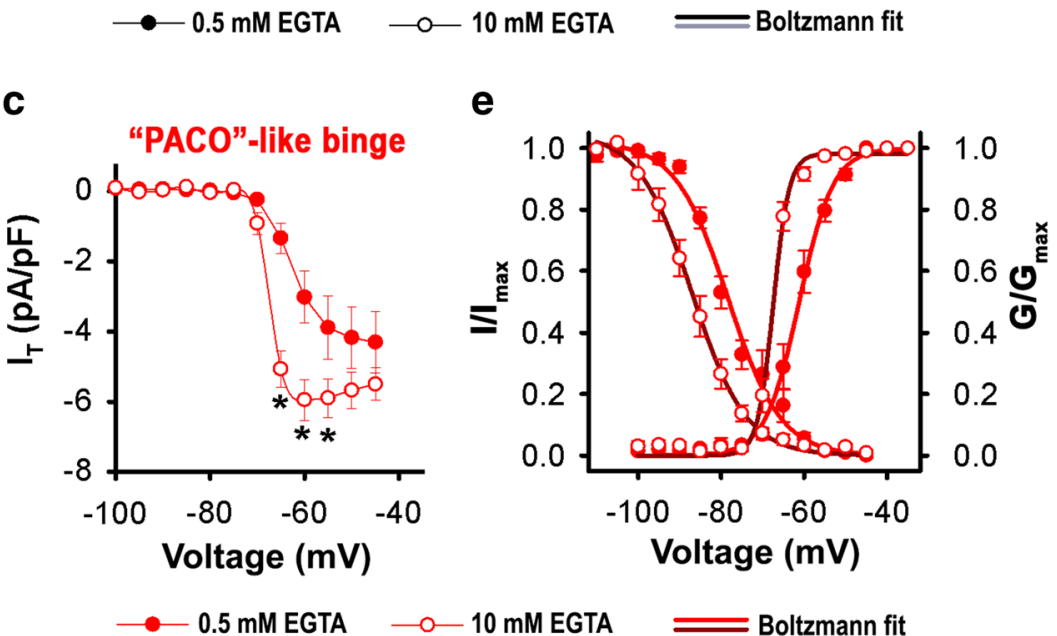

$0.5 \mathrm{mM}$ EGTA $\rightleftharpoons 10 \mathrm{mM}$ EGTA

g

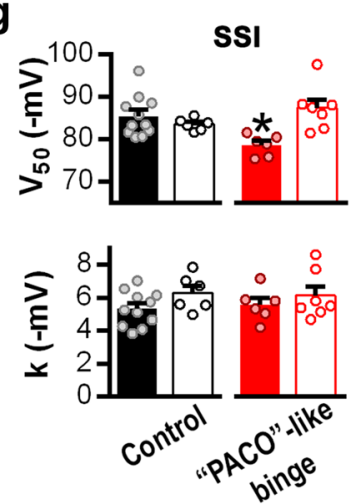

Fig. 5 Altered modulation of T-type voltage-gated calcium currents in ventrobasal neurons by intracellular calcium levels after an acute "PACO"-like binge treatment. a Left: Steady-state activation protocol (SSA). Center: average $\mathrm{I}_{\mathrm{T}}$ traces from a control treated VB neurons recorded using EGTA $0.5 \mathrm{mM}$ and $10 \mathrm{mM}$ in the intracellular pipette solution. Right: Average $\mathrm{I}_{\mathrm{T}}$ traces from a "PACO"-like binge treated VB neurons recorded using EGTA $0.5 \mathrm{mM}$ and $10 \mathrm{mM}$ in the pipette solution. b Current-voltage (I-V) curve of $\mathrm{I}_{\mathrm{T}}$ currents from control treated VB neurons recorded using EGTA $0.5 \mathrm{mM}$ (empty black dots; $n=11$ ) or EGTA $10 \mathrm{mM}$ (solid black dots; $n=6$ ). No significant differences were observed ( $p>0.05$, two-way RM ANOVA). c Current-voltage (I-V) curve of $\mathrm{I}_{\mathrm{T}}$ from "PACO"-like binge treated VB neurons recorded using EGTA $0.5 \mathrm{mM}$ (empty red dots; $n=6$ ) or EGTA $10 \mathrm{mM}$ (solid red dots;

$\mathrm{Ca}_{\mathrm{V}} 3.1$ (T-type, alpha1G isoform) protein level was increased by sub-chronic administration of cocaine. In addition, we found a profound reduction of $\mathrm{I}_{\mathrm{H}}$ density with the concomitant decrease of HCN2 mRNA level and a hyperpolarizing shift of $n=7)$ in the pipette solution. *Significantly different from EGTA $0.5 \mathrm{mM}, p<0.01$. Two-way RM ANOVA, testing voltages ( -65 to $\left.50 \mathrm{mV}, F_{(3,30)}: 16.17\right)$ and treatments $\left(F_{(1,30)}: 9.92\right)$. There was a statistically significant interaction between the applied voltages and treatments $\left(F_{(3,30)}: 6.04\right)$. d Overlapping steady-state activation (SSA) and inactivation (SSI) curves of average values (dots) and fitting to a Boltzmann equation (lines) for $\mathrm{I}_{\mathrm{T}}$ in control-treated $\mathrm{VB}$ neurons recorded using $0.5 \mathrm{mM}$ (filled dots) or $10 \mathrm{mM}$ EGTA (empty dots) in the pipette solution. e Same as in plot (d) for "PACO"-like binge treated neurons represented in red. $\mathbf{f}$ and $\mathbf{g}$ Comparison of average $\mathrm{V}_{50}$ and $\mathrm{k}$ parameters from Boltzmann fitting corresponding to plots (d) and (e). *Significantly different $(p<0.05$, ANOVA, see Table 2$)$

its steady-state activation curve. Therefore, in response to an inhibitory input, all these conditions generate a weak depolarizing force that would decrease the open probability of T-type $\mathrm{Ca}^{2+}$ channels, shaping LTS-associated $\mathrm{Ca}^{2+}$ 
Table 2 Comparison of T-type current steady-state parameters of activation and inactivation in dialyzed neurons with either 0.5 or $10 \mathrm{mM}$ EGTA for both control and "PACO" like binge treatments

\begin{tabular}{|c|c|c|c|c|c|}
\hline \multirow[b]{2}{*}{ EGTA concentration } & \multicolumn{2}{|l|}{ Control } & \multicolumn{2}{|c|}{ "PACO"-like binge } & \multirow[t]{2}{*}{ ANOVA $F$ statistics } \\
\hline & $0.5 \mathrm{mM}$ & $10 \mathrm{mM}$ & $0.5 \mathrm{mM}$ & $10 \mathrm{mM}$ & \\
\hline $\mathrm{V}_{50 \text { act. }}(\mathrm{mV})$ & $-65.2 \pm 1.5(10)$ & $-65 \pm 1.7(6)$ & $-60.7 \pm 1.7(6)^{*}$ & $-67.5 \pm 0.5(7)$ & $F_{3,25}=3.284$ \\
\hline$K_{\text {act. }}(\mathrm{mV})$ & $2.3 \pm 0.2(10)$ & $1.6 \pm 0.3(6)$ & $4.0 \pm 0.5(6)^{*}$ & $1.8 \pm 0.2(7)$ & $F_{3,25}=9.881$ \\
\hline $\mathrm{V}_{50 \text { inact. }}(\mathrm{mV})$ & $-85.5 \pm 1.4(11)$ & $-83.5 \pm 0.6(6)$ & $-78.7 \pm 1.0(6)^{*}$ & $-87.4 \pm 2(7)$ & $F_{3,26}=5.418$ \\
\hline$K_{\text {inact. }}(\mathrm{mV})$ & $-5.3 \pm 0.3(11)$ & $-6.3 \pm 0.4(6)$ & $-5.6 \pm 0.4(6)$ & $-6.1 \pm 0.5(7)$ & $F_{3,26}=1.203$ \\
\hline
\end{tabular}

Biophysical parameters $\left(\mathrm{V}_{50}\right.$ and slope factor $\left.k\right)$ were obtained from the fit of activation and steady-state inactivation curves with the Boltzmann function. $* p<0.05$, ANOVA

transients as observed in controls despite having an increased T-type current density. This effect was exclusively dependent on the combination of the psichostimulants; separately administration of cocaine or caffeine did not produce any effect on $\mathrm{I}_{\mathrm{H}}$.

Our results showed changes in the intrinsic properties of the VB neurons that persist after 24-h of a single (acute) or a chronic "PACO"-like binge consumption. We found that the input membrane resistance decreased after an acute binge, whereas it increased when the administration becomes chronic. Accordingly, we observed a binge-dependent regulation of $\mathrm{I}_{\mathrm{H}}$ density, while it was increased by an acute binge, it was decreased by a chronic one. $\mathrm{I}_{\mathrm{H}}$-mediated alterations in membrane resistance will determine how the neurons respond to incoming stimulation (Magee 1998; Kase and Imoto 2012). We found that the membrane excitability decreased after an acute "PACO"-like binge administration, while it increased after a chronic administration. Furthermore, we observed alterations in the threshold of action potentials (APs). The increase of basal $\left[\mathrm{Ca}^{2+}\right]_{i}$ in VB neurons $24-\mathrm{h}$ after the systemic administration of an acute "PACO"-like binge might potentiate intracellular $\mathrm{Ca}^{2+}$ mediated inhibition of high-voltageactivated $\mathrm{Ca}^{2+}$ channels (Rankovic et al. 2010) and voltagedependent $\mathrm{Na}^{+}$channels (Santarelli et al. 2007; Casini et al. 2009; Ulyanova and Shirokov 2018), blunting membrane depolarization mediated by these channels and decreasing the excitability of thalamocortical neurons, as we observed after an acute "PACO"-like binge. In addition, TREK $\mathrm{K}^{+}$channels are expressed in thalamocortical VB neurons (Meuth et al. 2006; Budde et al. 2008) and they have been described to influence the time-dependence of APs (Corbin-Leftwich et al. 2018). Caffeine has been reported to inhibit TREK$1 \mathrm{~K}^{+}$channels in a concentration- and cAMP-dependent manner (reviewed by Boison 2011).

Overall, our results showed that an acute "PACO"-like binge administration produced notorious alterations in the physiology of VB neurons, including enhancements of basal $\left[\mathrm{Ca}^{2+}\right]_{\mathrm{i}}$, upregulation of $\mathrm{I}_{\mathrm{H}}$ density, and changes in biophysical properties of $\mathrm{I}_{\mathrm{T}}$ that increased T-type "window currents." As a result, these alterations ultimately increased $\mathrm{Ca}^{2+}$ transients (LTS) associated to $\mathrm{H}$ and T-type currents and reduced the membrane excitability. Homeostatic mechanisms arise when the administration becomes chronic, such as downregulation of intracellular basal $\left[\mathrm{Ca}^{2+}\right]$ to normal levels and reduction of $\mathrm{I}_{\mathrm{H}}$ density, which not only restablished the LTS-associated $\mathrm{Ca}^{2+}$ transients as observed in controls, but also increased the membrane excitability to values even higher than control.

\section{Neuronal thalamocortical alterations contributed to sleep/wake transitions changes by chronic "PACO"- like binge treatments}

Voltage-gated ionic channels have been extensively described to explain neuronal excitability, endowing them with auto rhythmic membrane oscillatory capabilities (Llinás 1988; 2005). Synaptic receptors mediate functional contacts between neurons, spreading oscillations throughout neuronal networks. In such networks, auto rhythmic neurons might either act as oscillators/pacemakers or as resonators (Llinás 1988; Llinás et al. 2005).

Coincidence detection by co-activation of the "specific" (i.e., VB relay thalamocortical neurons) and the "non-specific" (intralaminar) thalamic nuclei at gamma band frequencies has been proposed as the basis for the temporal conjunction that supports cognitive binding in the brain (Llinás et al. 2002). Abnormal low-frequency oscillatory activity of thalamocortical neurons, due to enhanced T-type calcium channel activation, has been related to altered thalamocortical dynamics described as the basis for several types of neurological and neuropsychiatric conditions, collectively named thalamocortical dysrhythmia syndrome (Llinás et al. 1999, 2005). "PACO"-like administrations described in this work mediated long-lasting, protracted activation of such low voltage activated (LVA) T-type calcium currents and altered $\mathrm{I}_{\mathrm{H}}$ byophisics in VB thalamocortical neurons. These alterations could result in a thalamocortical stable dynamic attractor state of low-frequencies, that would be relayed from the thalamus to the cortical mantle (i.e., a dysrhythmic mechanism 
a

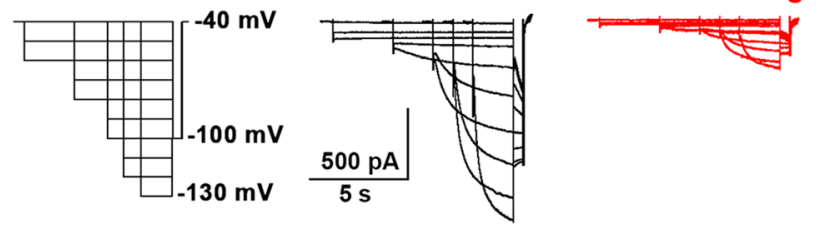

C

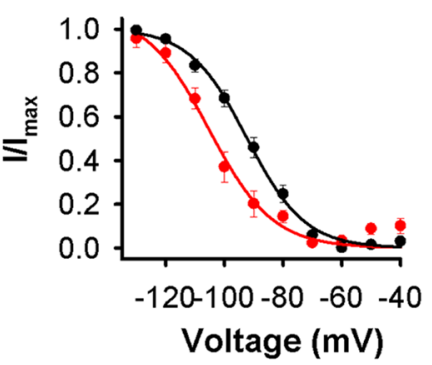

e

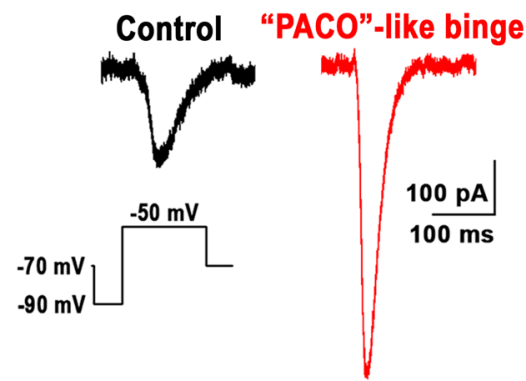

g

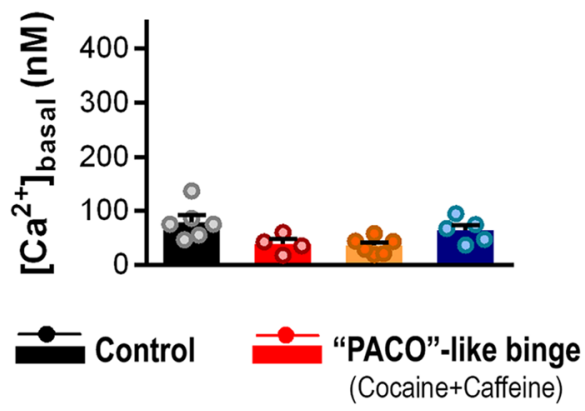

$\mathbf{f}$

h b

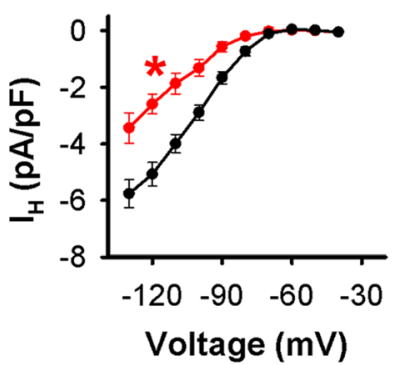

d

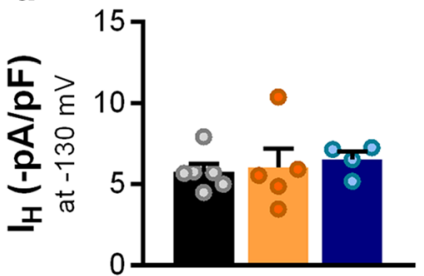

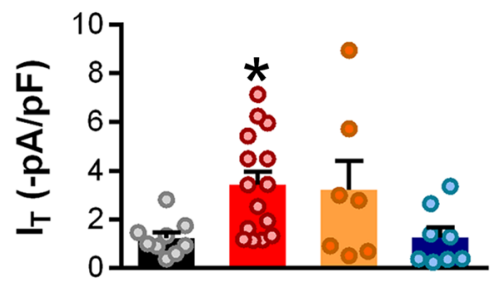

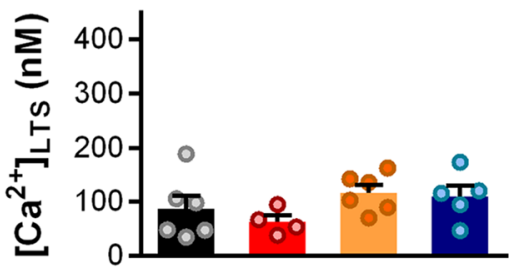

Cocaine Caffeine

Fig. 6 Chronic "PACO"-like binge administration altered H current density in VB neurons. a Activation protocol (left plot) of HCNmediated currents $\left(\mathrm{I}_{\mathrm{H}}\right)$. Average traces of $\mathrm{I}_{\mathrm{H}}$, comparing VB neurons recorded from mice treated with a chronic "PACO"-like binge (red lines, right plot) and controls (black lines, middle plot). Note how "PACO"-like binge treated $\mathrm{VB}$ neurons presented less $\mathrm{I}_{\mathrm{H}}$. b Average $\mathrm{I}_{\mathrm{H}}$-voltage relationship (I-V curve) for control (black, $n=6$ ) vs. "PACO"-like binge (red, $n=5)$ treatments. *Significantly different from control, $p<0.001$. Twoway RM ANOVA, testing voltages ( -90 to $\left.-130 \mathrm{mV}, F_{(4,36)}: 162.89\right)$ and treatments $\left(F_{(1,36)}: 31.62\right)$. There was a statistically significant interaction between the applied voltages and treatments $\left(F_{(4,36)}: 24.53\right)$. c Steady-state activation (SSA) curves for control (black, $n=6$ ) vs. "PACO"-like binge (red, $n=5$ ) treatments. *Significantly different from control. Right bar plots representing average $\mathrm{V}_{50}$ and $\mathrm{k}$, comparing control (black bar) and "PACO"-like binge (red bar). *Significantly different from control, $p<0.01$. Student's $t$ test, $\mathrm{t}_{9}=3.7$. $\mathrm{d}$ Bar plots comparing the
$\mathrm{I}_{\mathrm{H}}$ density at $-130 \mathrm{mV}$ for controls $(n=6)$ and separately administration of cocaine $(n=5)$ or caffeine $(n=4)(p>0.05$, ANOVA). e Representative T-type $\mathrm{Ca}^{2+}$ current trace for control and "PACO"-like binge treatments. $\mathrm{I}_{\mathrm{T}}$ was evoked by a voltage step from -90 to $50 \mathrm{mV}$. f Bar plots comparing the $\mathrm{I}_{\mathrm{T}}$ density at $-50 \mathrm{mV}$ for controls $(n=9)$, "PACO"-like binge $(n=15)$ and separately administration of cocaine $(n=7)$ or caffeine $(n=8)$. *Significantly different from control and caffeine, $p<0.05$, Kruskal-Wallis ANOVA on Ranks, $\mathrm{H}_{3}=10.843$. Calcium imaging: $\mathbf{g}$ basal intracellular calcium concentration $\left(\left[\mathrm{Ca}^{2+}\right]_{\text {basal }}\right)($ Mean $\pm \mathrm{SEM})$ presented for control (black, $\left.n=6\right)$, "PACO"-like (red, $n=4$ ), cocaine (yellow, $n=6$ ) and caffeine (blue, $n=4)$ treatments $\left(p>0.05\right.$, ANOVA). h LTS-associated $\mathrm{Ca}^{2+}$ transients $\left(\left[\mathrm{Ca}^{2+}\right]_{\mathrm{LTS}}\right)(\mathrm{Mean} \pm \mathrm{SEM})$ values are presented for control (black, $\left.n=6\right)$, "PACO"-like (red, $n=4$ ), cocaine (yellow, $n=6$ ) and caffeine (blue, $n=$ $5)$ treatments $(p>0.05$, ANOVA) 
a

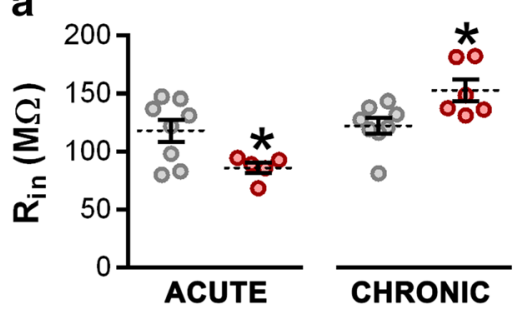

b

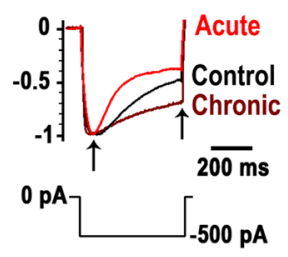

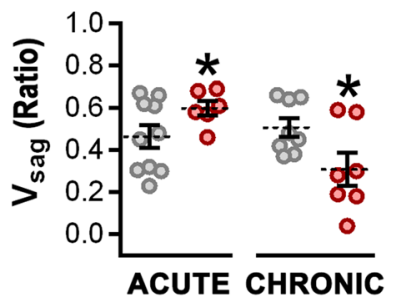

C<smiles>CC=C[Co]</smiles>

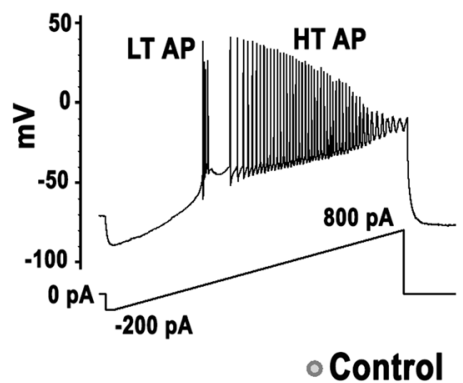

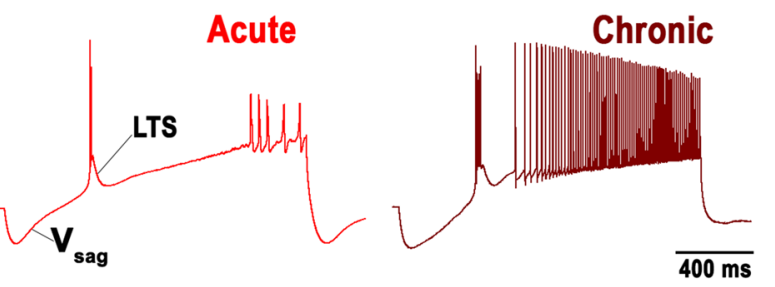

- Control

- "PACO"-like binge

(Cocaine+Caffeine)

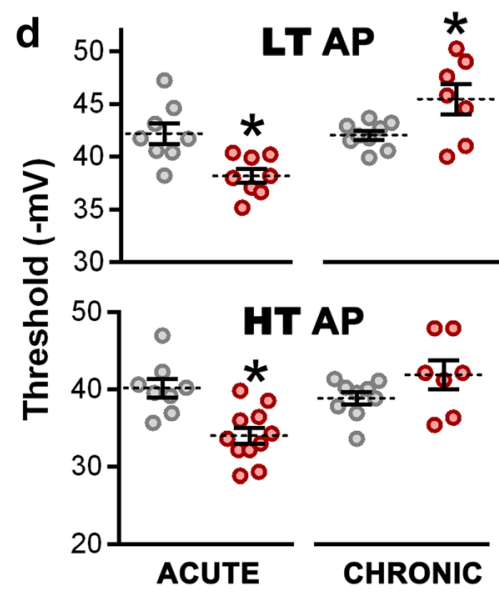

Fig. 7 Membrane excitability was altered 24-h after either acute or chonic "PACO"-like binge administration in VB neurons. a Input resistance $\left(\mathrm{R}_{\text {in }}\right)$ of VB neurons recorded after acute an chronic treatments, calculated as described in "Materials and Methods." Left: scatter plots (Mean \pm SEM) comparing: control (black, $n=8$ ) and "PACO"-like (red, $n=5)$ binges for acute treatments. * $p<0.05$, Student's $t$ test, $t_{11}=2.47$. Right: scatter plots (Mean \pm SEM) comparing: control (black, $n=8$ ) and "PACO"-like (red, $n=6$ ) binges for chronic treatments. $* p<0.05$, Student's $t$ test, $t_{12}=-2.70$. b Left: average volage traces of VB neurons recorded in current-clamp for control (black line), acute (red line) and chronic (maroon line) "PACO"-like binge treatments. Associated $\mathrm{HCN}$-mediated currents induced voltage rectification (Voltage sag, $\mathrm{V}_{\text {sag }}$ ), observed after a hyperpolarizing square pulse ($500 \mathrm{pA}$ ). Normalized traces are shown, see the small sag recorded after a chronic treatment. Right: voltage sag was calculed as $\left[\left(\mathrm{V}_{\text {peak }}-\mathrm{V}_{\mathrm{ss}}\right) / \mathrm{V}_{\text {peak }}\right]$, where $V_{\text {peak }}$ is the maximum instantaneous value (peak voltage) and $V_{s s}$ the voltage reached at the steady state (see black arrows). Scatter plots (Mean \pm SEM) comparing acute ( $n=10$ for control and $n=6$ for treated) and chronic ( $n=8$ for control and $n=7$ for treated) binges versus control condition. ${ }^{*} p<0.05$, Student's $t$ test, $t_{14}=-1.8$ for acute binges, $t_{13}=2.28$ for chronic binges. c Representative current ramp stimulus (ramp rate of $0.67 \mathrm{pA} / \mathrm{ms}$ ) applied after hyperpolarizing the membrane ( $-200 \mathrm{pA}$ for $50 \mathrm{~ms}$ ) to activate underlying $\mathrm{H}$ - and $\mathrm{T}$-type channels for control (black line), acute (red line), or chronic (maroon line) "PACO"-like binges. Action potentials triguered by a

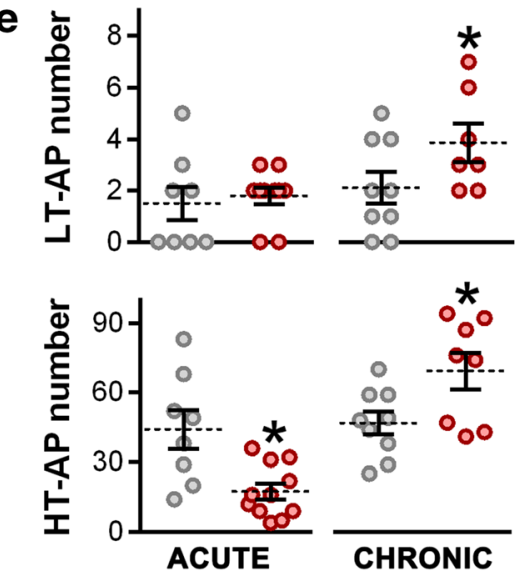

low-theshold spike (LTS) were called low-threshold action potentials (LT AP) and those triguered later were called high-treshold action potentials (HT AP). See the $V_{\text {sag }}$ recorded after an acute "PACO"-like binge. $\mathbf{d}$ Top. Left: scatter plots (Mean \pm SEM) comparing the voltage threshold of LT AP for acute controls $(n=8)$ and "PACO"-like $(n=8)$ binges. * $p<0.05$, Student's $t$ test, $t_{14}=3.39$. Right: scatter plots (Mean \pm SEM) comparing the voltage threshold of LT AP for chronic controls $(n=9)$ and "PACO"-like $(n=7)$ binges. $* p<0.05$, Student's $t$ test, $\mathrm{t}_{14}=-2.52$. Bottom. Left: Scatter plots (Mean \pm SEM) comparing the voltage threshold of HT AP for acute controls $(n=8)$ and "PACO"-like $(n=8)$ binges. $* p<0.05$, Student's $t$ test, $t_{17}=3.83$. Right: scatterplots (Mean \pm SEM) comparing the voltage threshold of HT AP for chronic controls $(n=9)$ and "PACO"-like $(n=7)$ binges $(p>0.05$, MannWhitney Rank Sum Test). e Top. Left: scatter plots (Mean \pm SEM) comparing the number of LT AP for acute controls $(n=8)$ and "PACO"-like $(n=10)$ binges binges ( $p>0.05$, Mann-Whitney Rank Sum Test). Right: scatter plots (Mean $\pm \mathrm{SEM}$ ) comparing the number of LT AP for chronic controls $(n=9)$ and "PACO"-like $(n=7)$ binges. * $p<0.05$, Student's $t$ test, $t_{14}=-1.84$. Bottom. Left: scatter plots (Mean \pm SEM) comparing the number of HT AP for acute controls $(n=8)$ and "PACO"-like $(n=11)$ binges. * $p<0.05$, Student's $t$ test, $t_{17}=3.28$. Right: scatter plots (Mean \pm SEM) comparing the number of HT AP for chronic controls $(n=9)$ and "PACO"-like $(n=8)$ binges. $* p<0.05$, Student's i test, $t_{15}=-2.48$ 
Fig. 8 Effects of chronic binge treatments on awake, NREM and REM sleep phases during electroencephalography recordings in mice. a Mean percentage of time in the awake stage plotted for every hour of 14 $\mathrm{h}$ recordings the transition from $18 \mathrm{~h}$ of the previous day until $8 \mathrm{~h}$ of the next day comparing mice $24 \mathrm{~h}$ after chronically treated with a "PACO"-like binge (red circles) versus vehicle (saline, black circles). Note that upper bar represents light (empty bar)/dark (filled bar) status during recordings. b Mean total awake time from cocaine+caffeine (red bar) and saline (black bar). *Significantly different from saline (Student's $t$ test; $t=4.5 ; p<0.001)$. $\mathbf{c}$ and $\mathbf{d}$ Same for NREM sleep. *Significantly different from saline (Student's $t$ test, $\mathrm{df}=13 ; t=$ 2.6; $p<0.05)$. e and $\mathbf{f}$ Same for REM sleep a

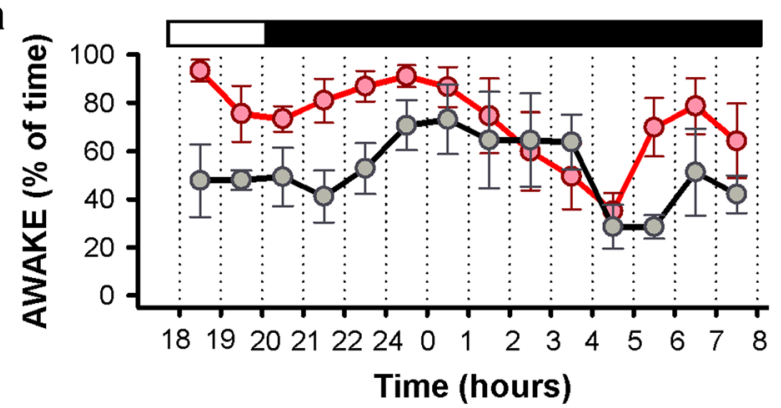

$\stackrel{-\infty}{-}$ Control

C

e

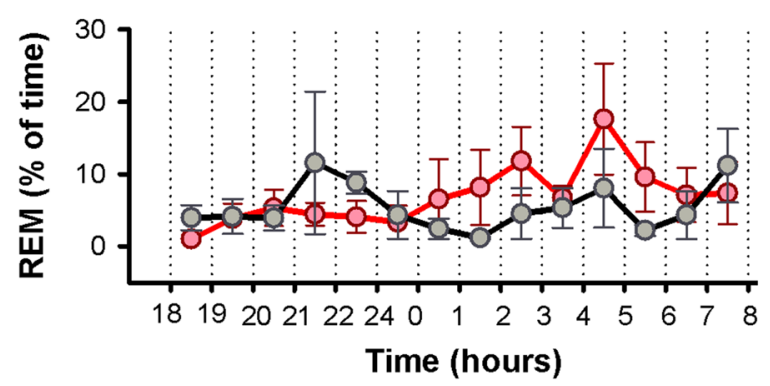

f

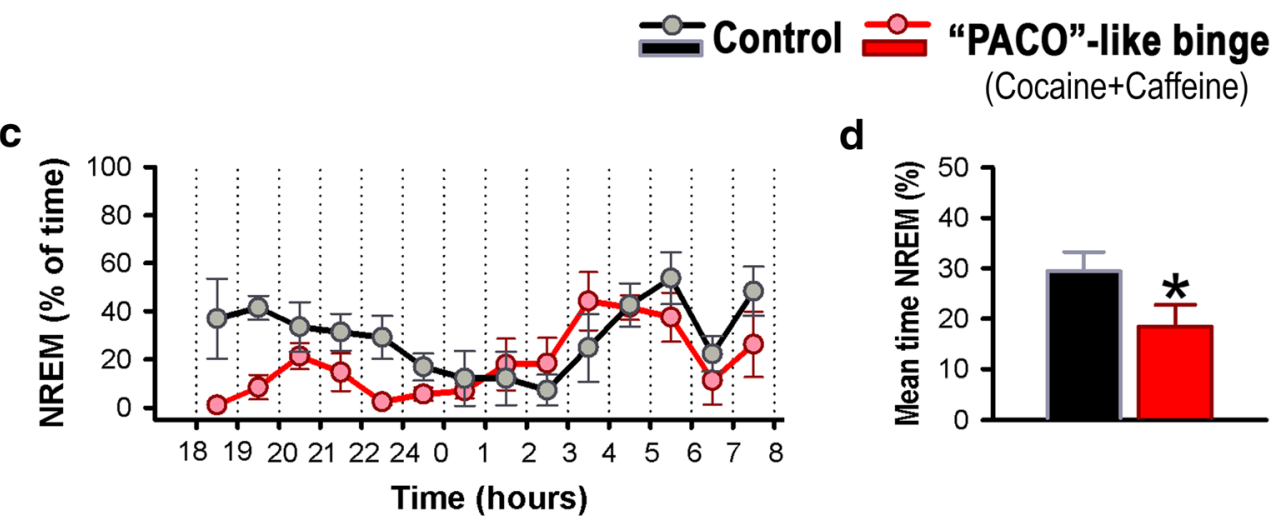

b

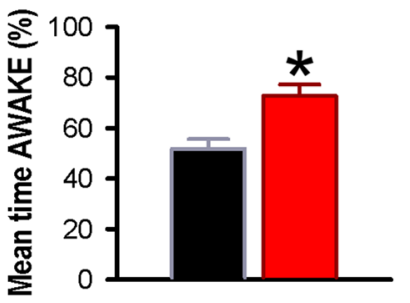

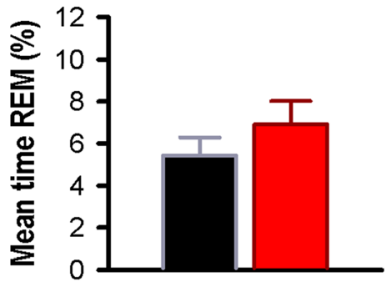

originated in a 'bottom-up' fashion). On the other hand, robust low-frequency and high-frequency interaction between nearby cortical columns generates asymmetric cortical inhibition called the edge-effect, a condition akin to a cortical correlation of thalamocortical dysrhythmia syndrome originated in a "top-down" fashion (Llinás et al. 2005). This contrast between "PACO"-like mediated mismatched inputs to the cortex is thought to produce alterations of sensory inputs processing as well as abrupt changes in sleep/wake transitions in the EEG. These mechanisms might result in long-lasting, potentially permanent changes in thalamocortical-cortithalamic processing.

Thalamocortical and striatal-cortical neurons have been described to be robustly interconnected (Albin et al. 1989). Both thalamocortical and striatal neurons have been described to be modulated by extracellular, synaptic monoaminergic augmentation mediated by cocaine (Urbano et al. 2015; Bisagno et al. 2016; Urbano and Bisagno 2017). We have previously described that "PACO"-like binge increased hyperlocomotion (Muñiz et al. 2016) and altered the expression of genes involved in glutamatergic and dopaminergic neurotransmission in the mesolimbic reward system (Muñiz et al. 2017). Furthermore, both caffeine and serotonin receptors have been described to modulated VB neurons (Goitia et al. 2016).

T-type and $\mathrm{HCN}$ channels are physically and functionally associated (Huang et al. 2011; Fan et al. 2017) to underlie lowfrequency oscillatory activity at the thalamocortical level that can be characterized using electroencephalography (EEG) (Llinás et al. 2007; Urbano et al. 2009; Huang et al. 2011). Indeed, T-type channels have been described as key elements involved in the sensitivity to psychostimulants (Bisagno et al. 2010; Goitia et al. 2013, 2016; Gangarossa et al. 2014). On the other hand, the amplitude of $\mathrm{I}_{\mathrm{H}}$ can be increased in the presence of a calcium-dependent increase in intracellular cAMP mediated by monoamine receptors such as norepinephrine and serotonin (Lüthi and McCormick 1999; Frère and Lüthi 2004), which causes failure to maintain the oscillatory trigger mode (Yue 2001). Dysregulation of $\mathrm{I}_{\mathrm{H}}$ has been linked to several neurological disorders with concomitant changes in thalamocortical/corticothalamic oscillatory activities such as 
in certain types of epilepsy (Cain et al. 2015; Zobeiri et al. 2018). After an acute administration of a "PACO"-like binge, the increase of $\mathrm{I}_{\mathrm{H}}$ density and the rightward shift of the steadystate properties of T-type channels will depolarize the threshold potential between the two firing modalities of VB neurons to values close to their resting potential. Therefore, VB neurons will be in transition between their firing modalities: oscillatory during slow (NREM) sleep and tonic during wakefulness and REM sleep. However, when the administration becomes chronic, VB neurons displayed a pronounced reduction of $\mathrm{I}_{\mathrm{H}}$ density, resulting in an increased input resistance that will alter the response to depolarizing inputs and the susceptibility for oscillations. The density and properties of $\mathrm{I}_{\mathrm{H}}$ are crucial factors in the generation and termination of sleeprelated thalamocortical activity (Kanyshkova et al. 2009). Since $\mathrm{I}_{\mathrm{H}}$ was sharply decreased 24 -h after a chronic "PACO"-like binge administration, we were interested in a further characterization using EEG. We observed alterations of wake/sleep transitions, the awake percentage of time was increased and the NREM sleep percentage of time was decreased after chronic "PACO"-like binge treatment, in accordance with the observed reduction of $\mathrm{I}_{\mathrm{H}}$ (Kanyshkova et al. 2009). Results presented here are consistent with a recent report showing increased time in the awake stage of rats 2 days after i.p. administration of "coca paste" adulterated with caffeine (Schwarzkopf et al. 2018). EEG recordings in rats have shown a decrease in the "power spectrum" of NREM sleep after a daily systemic (i.p.) administration of cocaine hydrochloride $(15 \mathrm{mg} / \mathrm{kg})$ (Binienda et al. 2006). In mice, when cocaine is administered systemically (i.p.), acute "binge" scheme significantly increased both $\mathrm{I}_{\mathrm{H}}$ and $\mathrm{I}_{\mathrm{T}}$ densities and NREM sleep low frequency oscilations, without changes in high frequencies (Urbano et al. 2009). In humans, cocaine administration suppresses REM sleep with subsequent rebound (that is, it increases the time in REM and decreases the latency to enter REM sleep [Morgan et al. 2008]. Withdrawal after chronic cocaine consumption altered sleep cytoarchitecture in patients who used cocaine (Angarita et al. 2014).

Sleep problems have been associated with the use of stimulants. Almost $70 \%$ of patients admitted for detoxification report sleep problems before admission, and $80 \%$ of those who report sleep problems are related to cocaine use, among others (Roncero et al. 2012). Alterations in the organization of sleep stages increased the risk of developing drug abuse disorders, and also chronic consumption of drugs of abuse lead to chronic sleep problems and diseases (Budney et al. 2003; Burke et al. 2008).

Further studies are needed in order to better characterize the role of cortical areas on the alterations observed here after combined cocaine and caffeine administration. Furthermore, unbalanced synaptic interactions between thalamocortical neurons after psychostimulant administsration need further study.

\section{Limitations and future perspectives}

The characterization of the functional alterations in the somatosensory thalamocortical system of animals exposed to cocaine and caffeine could contribute to the characterization of the harmful effects of these drugs, expanding the field of knowledge in the area of Neurobiology of drugs of abuse. Even though Argentina suffers from serious public health problems related to drugs of abuse and in particular the "PACO," the number of research groups that study these issues is small. More data comparing the effects of illegally consumed "PACO" samples obtained by South American judiciary branch with results described here is key. Future experiments are still needed in order to explore the possible role of membrane channels in charge of finely tune membrane potential (e.g., $\mathrm{K}_{2} \mathrm{P}, \mathrm{HCN}$, leak channels) on "PACO"-mediated thalamocortical deleterious effects.

\section{Conclusions}

Our results showed changes in the intrinsic properties of the ventrobasal nucleus neurons 24-h after either acute or chronic binge administrations of combined cocaine and caffeine ("PACO"-like binge). Acute treatments increased H-current density mediated by HCN channels and enhanced basal $\left[\mathrm{Ca}^{2+}\right]_{\mathrm{i}}$ that modulated biophysical properties of T-type $\mathrm{Ca}^{2+}$ channels. These alterations ultimately increased LTSassociated $\mathrm{Ca}^{2+}$ transients and reduced the membrane excitability of ventrobasal neurons. Chronic treatments exhibited a downregulation of basal $\left[\mathrm{Ca}^{2+}\right]_{\mathrm{i}}$ and a reduction of $\mathrm{I}_{\mathrm{H}}$ density, which not only restablished the LTS-associated $\mathrm{Ca}^{2+}$ transients as observed in controls, but also increased the membrane excitability. Chronic treatments were capable of not only altering intrinsic properties of thalamocortical neurons but also increasing awake percentage while reducing NREM sleep time during electroencephalography recordings.

Acknowledgments The authors would like remember our recently deceased colleague Dr. Carlota Gonzalez-Inchauspe. Carlota has been a brilliant and hardworking neuroscientist that has been working with us for a long time. Her experiments and data analysis made possible this paper. In the middle of the COVID-19 pandemic, Carlota has passed away last June 2020 just weeks away prior submission of this manuscript. In addition, the authors would like to thank Dr. Javier Muñiz and Maria Emilia Ferro for their help during initial setup of our electroencephalography rig. This work was supported by grants from FONCYT-Agencia Nacional de Promoción Científica y Tecnológica; Préstamo BID 1728 OC.AR.PICT [Grant numbers: 2016-1728 and 2018-1744]; and Argentina-Germany collaboration grant, CONICET-DFG-MINCYT [Grant number: 2016-23120160100012CO01] to Dr. Urbano. FONCYT-Agencia Nacional de Promoción Científica y Tecnológica; 
Préstamo BID 1728 OC.AR.PICT [Grant numbers: 2012-0924 and 20152594] to Dr. Bisagno. FONCYT-Agencia Nacional de Promoción Científica y Tecnológica; Préstamo BID 1728 OC.AR.PICT [Grant number: 2016-1799] to Dr. Perissinotti.

Authors' contributions Maria Celeste Rivero-Echeto: methodology, investigation, formal analysis, writing - review \& editing. Paula P. Perissinotti: methodology, investigation, formal analysis, writingoriginal draft. Carlota Gonzalez-Inchauspe: methodology, investigation \& formal analysis. Lucila Kargieman: formal analysis, writing - review \& editing. Veronica Bisagno: methodology, investigation, resources, supervision, funding acquisition, writing - review \& editing. Francisco J. Urbano: methodology, investigation, resources, supervision, project administration, funding acquisition, writing - original draft.

Funding This work was supported by grants from FONCYT-Agencia Nacional de Promoción Científica y Tecnológica; Préstamo BID 1728 OC.AR.PICT [Grant numbers: 2016-1728 and 2018-1744]; and Argentina-Germany collaboration grant, CONICET-DFG-MINCYT [Grant number: 2016-23120160100012CO01] to Dr. Urbano. FONCYT-Agencia Nacional de Promoción Científica y Tecnológica; Préstamo BID 1728 OC.AR.PICT [Grant numbers: 2012-0924 and 2015-2594] to Dr. Bisagno. FONCYT-Agencia Nacional de Promoción Científica y Tecnológica; Préstamo BID 1728 OC.AR.PICT [Grant number: 2016-1799] to Dr. Perissinotti.

\section{Compliance with ethical standards}

Research involving human participants and/or animals This article does not contain any studies with human participants performed by any of the authors. All procedures performed in studies involving animals (mice) were in accordance with the ethical standards of the Central Animal Facility at the University of Buenos Aires (animal protocol \#50-2015, and \#67-2015). Principles of mice care of the Central Animal Facility (University of Buenos Aires) were in accordance with the National Institutes of Health guide (NIH Publications, No. 8023, revised 1978) for the care and use of Laboratory animals, ARRIVE guidelines and CONICET (2003), and approved by its authorities using OLAW/ARENA directives (NIH, Bethesda, MD, USA). The experiments in this study complied with the current laws of Argentina. Authors have full control of all primary data and agree to allow the journal to review their data if requested.

Conflict of interest The authors declare that they have no conflict of interest.

\section{References}

Albin RL, Young AB, Penney JB (1989) The functional anatomy of basal ganglia disorders. Trends Neurosci 12(10):366-375. https://doi.org/ 10.1016/0166-2236(89)90074-x

Angarita GA, Canavan SV, Forselius E, Bessette A, Morgan PT (2014) Correlates of polysomnographic sleep changes in cocaine dependence: self-administration and clinical outcomes. Drug Alcohol Depend 143:173-180. https://doi.org/10.1016/j.drugalcdep.2014. 07.025

Aoyama K, Matsumura N, Watabe M, Wang F, Kikuchi-Utsumi K, Nakaki T (2011) Caffeine and uric acid mediate glutathione synthesis for neuroprotection. Neuroscience 181:206-215. https://doi.org/ 10.1016/j.neuroscience.2011.02.047

Asmara H, Micu I, Rizwan AP, Sahu G, Simms BA, Zhang FX, Engbers JDT, Stys PK, Zamponi GW, Turner RW (2017) A T-type channel- calmodulin complex triggers $\alpha$ CaMKII activation. Mol Brain 10(1): 37. https://doi.org/10.1186/s13041-017-0317-8

Behrendt R-P (2006) Dysregulation of thalamic sensory 'transmission' in schizophrenia: neurochemical vulnerability to hallucinations. J Psychopharmacol 20:356-372. https://doi.org/10.1177/ 0269881105057696

Bijlenga P, Liu J-H, Espinos E, Haenggeli CA, Fischer-Lougheed J, Bader CR, Bernheim L (2000) T-type alpha $1 \mathrm{H} \mathrm{Ca} 2+$ channels are involved in $\mathrm{Ca} 2+$ signaling during terminal differentiation (fusion) of human myoblasts. Proc Natl Acad Sci 97:7627-7632. https://doi. org/10.1073/pnas.97.13.7627

Binienda ZK, Pereira F, Alper K et al (2006) Adaptation to repeated cocaine administration in rats. Ann N Y Acad Sci 965:172-179. https://doi.org/10.1111/j.1749-6632.2002.tb04159.x

Bisagno V, Raineri M, Peskin V, Wikinski SI, Uchitel OD, Llinás RR, Urbano FJ (2010) Effects of T-type calcium channel blockers on cocaine-induced hyperlocomotion and thalamocortical GABAergic abnormalities in mice. Psychopharmacology 212:205-214. https:// doi.org/10.1007/s00213-010-1947-z

Bisagno V, González B, Urbano FJ (2016) Cognitive enhancers versus addictive psychostimulants: the good and bad side of dopamine on prefrontal cortical circuits. Pharmacol Res 109:108-118. https://doi. org/10.1016/j.phrs.2016.01.013

Boison D (2011) Methylxanthines, seizures, and excitotoxicity. In: Methylxanthines. Springer, Berlin Heidelberg, Berlin, Heidelberg, pp 251-266. https://doi.org/10.1007/978-3-642-13443-2 9

Brennan GP, Baram TZ, Poolos NP (2016) Hyperpolarization-activated cyclic nucleotide-gated $(\mathrm{HCN})$ channels in epilepsy. Cold Spring Harb Perspect Med 6:a022384. https://doi.org/10.1101/ cshperspect.a022384

Budde T, Coulon P, Pawlowski M, Meuth P, Kanyshkova T, Japes A, Meuth SG, Pape HC (2008) Reciprocal modulation of I h and I TASK in thalamocortical relay neurons by halothane. Pflugers Arch - Eur J Physiol 456:1061-1073. https://doi.org/10.1007/ s00424-008-0482-9

Budney AJ, Moore BA, Vandrey RG, Hughes JR (2003) The time course and significance of cannabis withdrawal. J Abnorm Psychol 112: 393-402. https://doi.org/10.1037/0021-843X.112.3.393

Burke CK, Peirce JM, Kidorf MS, Neubauer D, Punjabi NM, Stoller KB, Hursh S, Brooner RK (2008) Sleep problems reported by patients entering opioid agonist treatment. J Subs Abuse Treat 35:328-333. https://doi.org/10.1016/j.jsat.2007.10.003

Cadet JL, Bisagno V (2013) The primacy of cognition in the manifestations of substance use disorders. Front Neurol 4. https://doi.org/10. 3389/fneur.2013.00189

Cadet JL, Bisagno V, Milroy CM (2014) Neuropathology of substance use disorders. Acta Neuropathol 127:91-107. https://doi.org/10. 1007/s00401-013-1221-7

Cain SM, Tyson JR, Jones KL, Snutch TP (2015) Thalamocortical neurons display suppressed burst-firing due to an enhanced Ih current in a genetic model of absence epilepsy. Pflugers Arch - Eur J Physiol 467:1367-1382. https://doi.org/10.1007/s00424-014-1549-4

Casini S, Verkerk AO, van Borren MMGJ, van Ginneken ACG, Veldkamp MW, de Bakker JMT, Tan HL (2009) Intracellular calcium modulation of voltage-gated sodium channels in ventricular myocytes. Cardiovasc Res 81:72-81. https://doi.org/10.1093/cvr/ cvn274

Cazade M, Bidaud I, Lory P, Chemin J (2017) Activity-dependent regulation of T-type calcium channels by submembrane calcium ions. eLife 6:e22331. https://doi.org/10.7554/eLife.22331

Corbin-Leftwich A, Small HE, Robinson HH, Villalba-Galea CA, Boland LM (2018) A xenopus oocyte model system to study action potentials. J Gen Physiol 150:1583-1593. https://doi.org/10.1085/ jgp.201812146

Coulon P, Herr D, Kanyshkova T, Meuth P, Budde T, Pape HC (2009) Burst discharges in neurons of the thalamic reticular nucleus are 
shaped by calcium-induced calcium release. Cell Calcium 46:333346. https://doi.org/10.1016/j.ceca.2009.09.005

Crunelli V, Tóth TI, Cope DW, Blethyn K, Hughes SW (2005) The 'window' T-type calcium current in brain dynamics of different behavioural states: neuronal $I$ Twindow. JPhysiol 562:121-129. https://doi.org/10.1113/jphysiol.2004.076273

Deisseroth K, Bito H, Tsien RW (1996) Signaling from synapse to nucleus: postsynaptic CREB phosphorylation during multiple forms of hippocampal synaptic plasticity. Neuron 16:89-101. https://doi.org/ 10.1016/S0896-6273(00)80026-4

Devlin RJ, Henry JA (2008) Clinical review: major consequences of illicit drug consumption. Crit Care 12:202. https://doi.org/10.1186/ cc6166

Di Guilmi MN, Wang T, Inchauspe CG et al (2014) Synaptic gain-offunction effects of mutant Cav2.1 channels in a mouse model of familial hemiplegic migraine are due to increased basal [Ca2+]i. J Neurosci 34:7047-7058. https://doi.org/10.1523/JNEUROSCI. 2526-13.2014

Du C, Yu M, Volkow ND et al (2006) Cocaine increases the intracellular calcium concentration in brain independently of its cerebrovascular effects. J Neurosci 26:11522-11531. https://doi.org/10.1523/ JNEUROSCI.3612-06.2006

Fan J, Gandini MA, Zhang F-X, Chen L, Souza IA, Zamponi GW (2017) Down-regulation of T-type Cav3.2 channels by hyperpolarizationactivated cyclic nucleotide-gated channel 1 (HCN1): evidence of a signaling complex. Channels 11:434-443. https://doi.org/10.1080/ 19336950.2017.1326233

Fontanez DE, Porter JT (2006) Adenosine A1 receptors decrease thalamic excitation of inhibitory and excitatory neurons in the barrel cortex. Neuroscience 137:1177-1184. https://doi.org/10.1016/j. neuroscience.2005.10.022

Fredholm BB (1995) Adenosine, adenosine receptors and the actions of caffeine. Pharmacol Toxicol 76:93-101. https://doi.org/10.1111/j. 1600-0773.1995.tb00111.x

Fredholm BB, Bättig K, Holmén J, Nehlig A, Zvartau EE (1999) Actions of caffeine in the brain with special reference to factors that contribute to its widespread use. Pharmacol Rev 51:83-133

Frère SGA, Lüthi A (2004) Pacemaker channels in mouse thalamocortical neurones are regulated by distinct pathways of cAMP synthesis: cAMP signalling in thalamocortical neurones. $J$ Physiol 554:111-125. https://doi.org/10.1113/jphysiol.2003. 050989

Gangarossa G, Laffray S, Bourinet E, Valjent E (2014) T-type calcium channel Cav3.2 deficient mice show elevated anxiety, impaired memory and reduced sensitivity to psychostimulants. Front Behav Neurosci 8. https://doi.org/10.3389/fnbeh.2014.00092

Garaschuk O, Yaari Y, Konnerth A (1997) Release and sequestration of calcium by ryanodine-sensitive stores in rat hippocampal neurones. J Physiol 502:13-30. https://doi.org/10.1111/j.1469-7793.1997. 013bl.x

Goitia B, Raineri M, González LE, Rozas JL, Garcia-Rill E, Bisagno V, Urbano FJ (2013) Differential effects of methylphenidate and cocaine on GABA transmission in sensory thalamic nuclei. $\mathrm{J}$ Neurochem 124:602-612. https://doi.org/10.1111/jnc.12113

Goitia B, Rivero-Echeto MC, Weisstaub NV, Gingrich JA, Garcia-Rill E, Bisagno V, Urbano FJ (2016) Modulation of GABA release from the thalamic reticular nucleus by cocaine and caffeine: role of serotonin receptors. J Neurochem 136:526-535. https://doi.org/10.1111/ jnc. 13398

Hanson GR, Jensen M, Johnson M, White HS (1999) Distinct features of seizures induced by cocaine and amphetamine analogs. Eur J Pharmacol 377:167-173. https://doi.org/10.1016/S0014-2999(99) 00419-7

Heppert K, Davies M (1999) Simultaneous determination of caffeine from blood, brain and muscle using microdialysis in an awake rat and the effect of caffeine on rat activity. Curr Sep 18:3-8
Huang Z-L, Urade Y, Hayaishi O (2011) The role of adenosine in the regulation of sleep. CTMC 11:1047-1057. https://doi.org/10.2174/ 156802611795347654

Hughes SW, Cope DW, Tóth TI, Williams SR, Crunelli V (1999) All thalamocortical neurones possess a T-type $\mathrm{Ca}^{2+}$ 'window' current that enables the expression of bistability-mediated activities. J Physiol 517:805-815. https://doi.org/10.1111/j.1469-7793.1999. 0805s.x

Jahnsen H, Llinás R (1984a) Ionic basis for the electro-responsiveness and oscillatory properties of guinea-pig thalamic neurones in vitro. $\mathrm{J}$ Physiol 349:227-247. https://doi.org/10.1113/jphysiol.1984. sp015154

Jahnsen H, Llinás R (1984b) Electrophysiological properties of guineapig thalamic neurones: an in vitro study. J Physiol 349:205-226. https://doi.org/10.1113/jphysiol.1984.sp015153

Kanyshkova T, Pawlowski M, Meuth P, Dube C, Bender RA, Brewster AL, Baumann A, Baram TZ, Pape HC, Budde T (2009) Postnatal expression pattern of HCN channel isoforms in thalamic neurons: relationship to maturation of thalamocortical oscillations. J Neurosci 29:8847-8857. https://doi.org/10.1523/JNEUROSCI.0689-09.2009

Kase D, Imoto K (2012) The role of HCN channels on membrane excitability in the nervous system. J Signal Transduc 2012:1-11. https:// doi.org/10.1155/2012/619747

Lambert RC, Bessaï T, Crunelli V, Leresche N (2014) The many faces of T-type calcium channels. Pflugers Arch - Eur J Physiol 466:415423. https://doi.org/10.1007/s00424-013-1353-6

Lazarus M, Shen H-Y, Cherasse Y, Qu WM, Huang ZL, Bass CE, Winsky-Sommerer R, Semba K, Fredholm BB, Boison D, Hayaishi O, Urade Y, Chen JF (2011) Arousal effect of caffeine depends on adenosine A2A receptors in the shell of the nucleus accumbens. J Neurosci 31:10067-10075. https://doi.org/10.1523/ JNEUROSCI.6730-10.2011

Llinás R (1988) The intrinsic electrophysiological properties of mammalian neurons: insights into central nervous system function. Science 242:1654-1664. https://doi.org/10.1126/science.3059497

Llinás RR, Leznik E, Urbano FJ (2002) Temporal binding via cortical coincidence detection of specific and nonspecific thalamocortical inputs: A voltage-dependent dye-imaging study in mouse brain slices. Proceedings of the National Academy of Sciences 99(1): 449-454. https://doi.org/10.1073/pnas.012604899

Llinás R, Urbano FJ, Leznik E, Ramírez RR, van Marle HJF (2005) Rhythmic and dysrhythmic thalamocortical dynamics: GABA systems and the edge effect. Trends Neurosci 28:325-333. https://doi. org/10.1016/j.tins.2005.04.006

Llinás RR, Ribary U, Jeanmonod D, Kronberg E, Mitra PP (1999) Thalamocortical dysrhythmia: A neurological and neuropsychiatric syndrome characterized by magnetoencephalography. Proceedings of the National Academy of Sciences 96:15222-15227. https://doi. org/10.1073/pnas.96.26.15222

Llinás RR, Choi S, Urbano FJ, Shin H-S (2007) Band deficiency and abnormal thalamocortical activity in P/Q-type channel mutant mice. Proc Natl Acad Sci U S A 104:17819-17824. https://doi.org/10. 1073/pnas.0707945104

López-Hill X, Prieto JP, Meikle MN, Urbanavicius J, Abin-Carriquiry JA, Prunell G, Umpiérrez E, Scorza MC (2011) Coca-paste seized samples characterization: chemical analysis, stimulating effect in rats and relevance of caffeine as a major adulterant. Behav Brain Res 221:134-141. https://doi.org/10.1016/j.bbr.2011.03.005

López-Rodriguez AB, Viveros M-P (2019) Bath salts and polyconsumption: in search of drug-drug interactions. Psychopharmacology 236:1001-1014. https://doi.org/10.1007/ s00213-019-05213-3

Lüthi A, McCormick DA (1999) Modulation of a pacemaker current through $\mathrm{Ca} 2+-$ induced stimulation of cAMP production. Nat Neurosci 2:634-641. https://doi.org/10.1038/10189 
Lüthi A, Bal T, McCormick DA (1998) Periodicity of thalamic spindle waves is abolished by ZD7288, a blocker of $I_{\mathrm{h}}$. J Neurophysiol 79: 3284-3289. https://doi.org/10.1152/jn.1998.79.6.3284

Magee JC (1998) Dendritic hyperpolarization-activated currents modify the integrative properties of hippocampal CA1 pyramidal neurons. J Neurosci 18:7613-7624. https://doi.org/10.1523/JNEUROSCI.1819-07613.1998

Marty A, Neher E (1985) Potassium channels in cultured bovine adrenal chromaffin cells. J Physiol 367:117-141. https://doi.org/10.1113/ jphysiol.1985.sp015817

Meuth SG, Kanyshkova T, Meuth P, Landgraf P, Munsch T, Ludwig A, Hofmann F, Pape HC, Budde T (2006) Membrane resting potential of thalamocortical relay neurons is shaped by the interaction among TASK3 and HCN2 channels. J Neurophysiol 96:1517-1529. https:// doi.org/10.1152/jn.01212.2005

Momin A, Cadiou H, Mason A, McNaughton PA (2008) Role of the hyperpolarization-activated current $I_{\mathrm{h}}$ in somatosensory neurons: role of $I_{\mathrm{h}}$ in nociception. J Physiol 586:5911-5929. https://doi. org/10.1113/jphysiol.2008.163154

Morgan PT, Pace-Schott EF, Sahul ZH, Coric V, Stickgold R, Malison RT (2008) Sleep architecture, cocaine and visual learning. Addiction 103:1344-1352. https://doi.org/10.1111/j.1360-0443. 2008.02233.x

Muñiz JA, Gomez G, González B, Rivero-Echeto MC, Cadet JL, GarcíaRill E, Urbano FJ, Bisagno V (2016) Combined effects of simultaneous exposure to caffeine and cocaine in the mouse striatum. Neurotox Res 29:525-538. https://doi.org/10.1007/s12640-0169601-0

Muñiz JA, Prieto JP, González B, Sosa MH, Cadet JL, Scorza C, Urbano FJ, Bisagno V (2017) Cocaine and caffeine effects on the conditioned place preference test: concomitant changes on early genes within the mouse prefrontal cortex and nucleus Accumbens. Front Behav Neurosci 11:200. https://doi.org/10.3389/fnbeh.2017.00200

Perissinotti PP, Ethington EG, Cribbs L, Koob MD, Martin J, PiedrasRentería ES (2014) Down-regulation of endogenous KLHL1 decreases voltage-gated calcium current density. Cell Calcium 55: 269-280. https://doi.org/10.1016/j.ceca.2014.03.002

Perissinotti PP, Rivero-Echeto MC, Garcia-Rill E, Bisagno V, Urbano FJ (2018) Leptin alters somatosensory thalamic networks by decreasing gaba release from reticular thalamic nucleus and action potential frequency at ventrobasal neurons. Brain Struct Funct 223:2499 2514. https://doi.org/10.1007/s00429-018-1645-x

Prieto JP, Scorza C, Serra GP, Perra V, Galvalisi M, Abin-Carriquiry JA, Piras G, Valentini V (2016) Caffeine, a common active adulterant of cocaine, enhances the reinforcing effect of cocaine and its motivational value. Psychopharmacology 233:2879-2889. https://doi.org/ 10.1007/s00213-016-4320-Z

Prieto JP, González B, Muñiz J, Bisagno V, Scorza C (2020) Molecular changes in the nucleus accumbens and prefrontal cortex associated with the locomotor sensitization induced by coca paste seized samples. Psychopharmacology 237:1481-1491. https://doi.org/10. 1007/s00213-020-05474-3

Rankovic V, Ehling P, Coulon P, Landgraf P, Kreutz MR, Munsch T, Budde $\mathrm{T}$ (2010) Intracellular $\mathrm{Ca}^{2+}$ release-dependent inactivation of $\mathrm{Ca}^{2+}$ currents in thalamocortical relay neurons. Eur J Neurosci 31: 439-449. https://doi.org/10.1111/j.1460-9568.2010.07081.x

Richter TA (2005) Low voltage-activated $\mathrm{Ca} 2+$ channels are coupled to $\mathrm{Ca} 2+$-induced $\mathrm{Ca} 2+$ release in rat thalamic midline neurons. J Neurosci 25:8267-8271. https://doi.org/10.1523/JNEUROSCI. 1942-05.2005

Roberts WM (1993) Spatial calcium buffering in saccular hair cells. Nature 363:74-76. https://doi.org/10.1038/363074a0

Roncero C, Grau-López L, Díaz-Morán S, Miquel L, Martínez-Luna N, Casas M (2012) Evaluation of sleep disorders in drug dependent inpatients (in spanish). Med Clin 138:332-335. https://doi.org/10. 1016/j.medcli.2011.07.015
Rozas JL, Goitia B, Bisagno V, Urbano FJ (2017) Differential alterations of intracellular $[\mathrm{Ca} 2+]$ dynamics induced by cocaine and methylphenidate in thalamocortical ventrobasal neurons. Transl Brain Rhythmicity 2. https://doi.org/10.15761/TBR.1000114

Santarelli VP, Eastwood AL, Dougherty DA, Horn R, Ahern CA (2007) A cation- interaction discriminates among sodium channels that are either sensitive or resistant to Tetrodotoxin block. J Biol Chem 282: 8044-8051. https://doi.org/10.1074/jbc.M611334200

Schwarzkopf N, Lagos P, Falconi A, Scorza C, Torterolo P (2018) Caffeine as an adulterant of coca paste seized samples: preclinical study on the rat sleep-wake cycle. Behav Pharmacol 29:519-529. https://doi.org/10.1097/FBP.0000000000000417

Steriade M, Amzica F (1996) Intracortical and corticothalamic coherency of fast spontaneous oscillations. Proc Natl Acad Sci U S A 93:25332538. https://doi.org/10.1073/pnas.93.6.2533

Ulyanova AV, Shirokov RE (2018) Voltage-dependent inward currents in smooth muscle cells of skeletal muscle arterioles. PLoS One 13: e0194980. https://doi.org/10.1371/journal.pone.0194980

Urbano FJ, Bisagno V (2017) Cocaine enhances gamma-aminobutyric acid release from reticular thalamic nucleus. In: The Neuroscience of Cocaine. Elsevier, pp. 511-518

Urbano FJ, Bisagno V, Wikinski SI, Uchitel OD, Llinás RR (2009) Cocaine acute "binge" administration results in altered thalamocortical interactions in mice. Biol Psychiatry 66:769-776. https://doi.org/10.1016/j.biopsych.2009.04.026

Urbano FJ, Bisagno V, González B, Celeste Rivero-Echeto M, Muñiz JA, Luster B, D'Onofrio S, Mahaffey S, Garcia-Rill E (2015) Pedunculopontine arousal system physiology-effects of psychostimulant abuse. Sleep Sci 8:162-168. https://doi.org/10. 1016/j.slsci.2015.09.004

Usachev Y, Shmigol A, Pronchuk N, Kostyuk P, Verkhratsky A (1993) Caffeine-induced calcium release from internal stores in cultured rat sensory neurons. Neuroscience 57:845-859. https://doi.org/10. 1016/0306-4522(93)90029-F

Verkhratsky A, Shmigol A (1996) Calcium-induced calcium release in neurons. Cell Calcium 19(1):1-14. https://doi.org/10.1016/s01434160(96)90009-3

Welsby PJ, Wang H, Wolfe JT, Colbran RJ, Johnson ML, Barrett PQ (2003) A mechanism for the direct regulation of T-type calcium channels by $\mathrm{Ca} 2+/$ calmodulin-dependent kinase II. J Neurosci 23(31):10116-10121. https://doi.org/10.1523/JNEUROSCI.23-3110116.2003

Yue B (2001) The role of H-current in regulating strength and frequency of thalamic network oscillations. Thalamus Relat Syst 1:95-103. https://doi.org/10.1016/S1472-9288(01)00009-7

Zhang X, Min X, Xu X et al (2016) ZD7288, a selective hyperpolarization-activated cyclic nucleotide-gated channel blocker, inhibits hippocampal synaptic plasticity. Neural Regen Res 11:779. https://doi.org/10.4103/1673-5374.182705

Zobeiri M, Chaudhary R, Datunashvili M, Heuermann RJ, Lüttjohann A, Narayanan V, Balfanz S, Meuth P, Chetkovich DM, Pape HC, Baumann A, van Luijtelaar G, Budde T (2018) Modulation of thalamocortical oscillations by TRIP8b, an auxiliary subunit for HCN channels. Brain Struct Funct 223:1537-1564. https://doi.org/ 10.1007/s00429-017-1559-z

Zobeiri M, Chaudhary R, Blaich A, Rottmann M, Herrmann S, Meuth P, Bista P, Kanyshkova T, Lüttjohann A, Narayanan V, Hundehege P, Meuth SG, Romanelli MN, Urbano FJ, Pape HC, Budde T, Ludwig A (2019) The hyperpolarization-activated HCN4 channel is important for proper maintenance of oscillatory activity in the Thalamocortical system. Cereb Cortex 29:2291-2304. https://doi. org/10.1093/cercor/bhz047

Publisher's note Springer Nature remains neutral with regard to jurisdictional claims in published maps and institutional affiliations. 